\title{
A Coal Burst Mitigation Strategy for Tailgate during Deep Mining of Inclined Longwall Top Coal Caving Panels at Huafeng Coal Mine
}

\author{
Guorui Feng $\mathbb{D}^{1}{ }^{1}$ Pengfei Wang $\mathbb{D}^{1},{ }^{1}$ Yoginder P. Chugh, ${ }^{2}$ Jingli Zhao, \\ Zhiqiang Wang, ${ }^{3}$ and Zhipeng Zhang ${ }^{5}$ \\ ${ }^{1}$ College of Mining Engineering, Taiyuan University of Technology, Taiyuan 030024, China \\ ${ }^{2}$ Department of Mining and Mineral Resources, Southern Illinois University, Carbondale, IL 62901, USA \\ ${ }^{3}$ College of Resource and Safety Engineering, China University of Mining and Technology-Beijing, Beijing 100083, China \\ ${ }^{4}$ Russian Academy of Natural Sciences, Moscow 119991, Russia \\ ${ }^{5}$ China Institute of Geo-Environment Monitoring, Beijing 100081, China
}

Correspondence should be addressed to Pengfei Wang; wangpengfei@tyut.edu.cn

Received 19 November 2017; Accepted 3 April 2018; Published 29 May 2018

Academic Editor: Longjun Dong

Copyright (C) 2018 Guorui Feng et al. This is an open access article distributed under the Creative Commons Attribution License, which permits unrestricted use, distribution, and reproduction in any medium, provided the original work is properly cited.

\begin{abstract}
A coal burst mitigation strategy for tailgate in mining of deep inclined longwall panels with top coal caving at Huafeng Coal Mine is presented in this paper. Field data showed that coal bursts, rib sloughing or slabbing, large convergence, and so forth frequently occurred within the tailgate entries during development and panel retreating employing standard longwall top coal caving (LTCC) layout which resulted in fatal injuries and tremendous profit loss. The contributing factors leading to coal bursts were analyzed. Laboratory tests, in situ measurement, and field observation demonstrate that the intrinsic bursting proneness of the coal seam and immediate roof stratum, deep cover, overlying ultrathick (500-800 m) conglomerate strata, faults, and, most importantly, improper panel layout led to coal bursts. By employing a new strategy, that is, longwall mining with split-level gateroads (LMSG), gateroads on either end of a LMSG panel are located at different levels within a coal seam, adjacent LMSG panels overlap end to end, and the tailgate of the adjacent new LMSG panel can be located below the headgate entry of the previous LMSG panel or may be offset horizontally with respect to it. Numerical modeling was carried out to investigate the stress distribution and yield zone development within surrounding rock mass which was validated by field investigation. The results indicate that standard LTCC system gave rise to high ground pressure around tailgate entries next to the gob, while LMSG tailgate entry below the gob edge was in a destressed environment. Therefore, coal bursts are significantly mitigated. Field practice of LMSG at Huafeng Coal Mine demonstrates how the new strategy effectively dealt with coal burst problems in mining of deep inclined longwall panels with a reduced incidence of ground control problems. The new strategy can potentially be applied in similar settings.
\end{abstract}

\section{Introduction}

Coal bursts, a common dynamic disaster often accompanied with sudden, quick, and violent ejection of coal or rock during exploitation of coal seams, often happen in complex ways under special conditions [1]. They are almost always accompanied by a loud noise, like an explosion, and ground vibration [2]. They result in injury if a miner is in the vicinity.
Figure 1 shows some major coal bursts that occurred in China.

Bursts in longwall mining have occurred mostly in gate pillars, in tailgates next to the gob, especially at the corner of the longwall face, and, to a lesser extent, in the longwall faces $[2,3]$. After the extraction of the first panel, as the second panel retreated, "bounces" consisting of sudden forceful vibrations became increasingly common on the tailgate end 


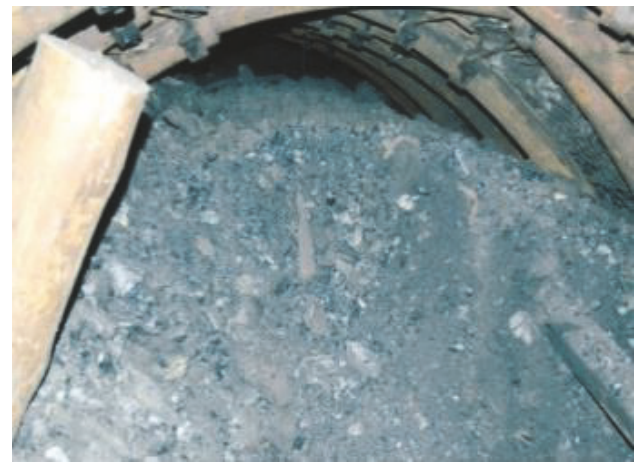

(a)

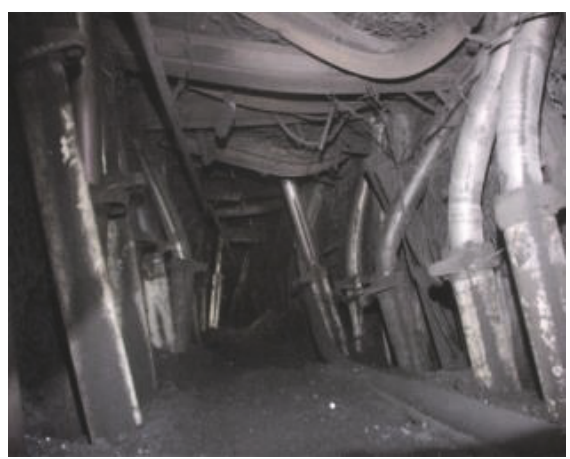

(c)

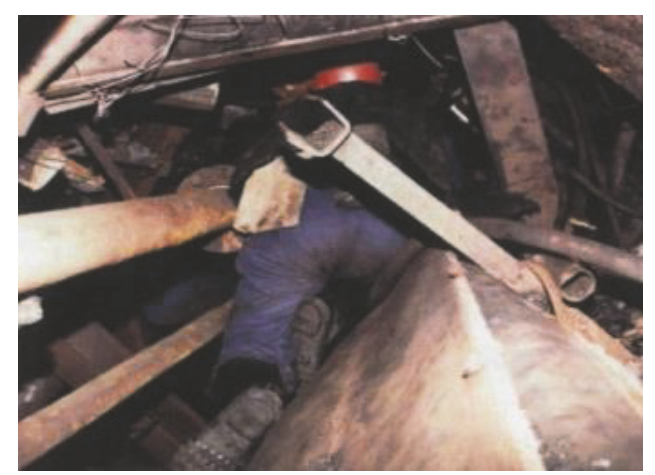

(b)

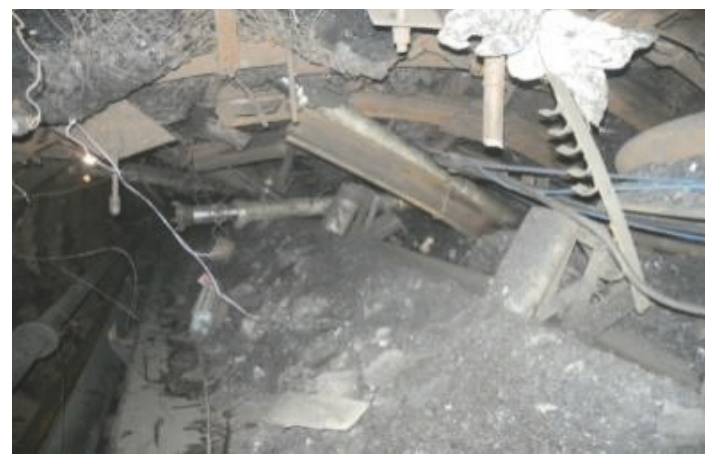

(d)

FIgure 1: Major coal bursts that occurred in China. (a) Coal burst at Meiyukou Coal Mine. (b) Coal burst at Laohutai Coal Mine. (c) Coal burst at Huating Coal Mine. (d) Coal burst at Qianqiu Coal Mine, Yima City, Henan Province (June 5, 2008, 21201 longwall panel; 565 m of gateroad was damaged; 11 miners were injured and 13 were killed).

of the panel. Typical pressure bursts frequently occur while the tailgate corner of the face is being cut by a longwall shearer. These locations directly affected by mining activity are subject to very high stresses.

Pillar design is the primary engineering control for minimizing the risk of pillar failure and coal bursts during retreat mining. Mining engineers endeavor to avoid "critical" pillars which are too large to yield nonviolently yet too small to support large abutment loads. The width-to-height ratios of such burst-prone, critical pillars normally exceeded 4 or 5 [4]. Many researchers proposed gob-side entry approaches to solve the ground control problems that occurred in gateroad associated with high abutment loading [5-11]. Gob-side entry is a combination of gateroad, pillar, and gob, which is a typical panel layout with slender pillar or artificial pillar or wall. Generally, there are two types of gob-side entry: (i) gob-side entry of the previous panel retained for the new panel, where constructing an artificial wall along the gob edge is usually required, and (ii) entry driven along gob side by leaving a slender pillar.

Stability and load bearing characteristics of the slender pillar depend on several factors including mechanical properties of the roof strata, cover depth, and panel geometry. Yan et al. [12] indicated that the bearing capacity of the slender pillar would decrease because both edges of the pillar will fracture. Due to the effect of abutment pressure movement of panel advance, the pillar next to the gob edge would experience serious deformation and fractures. The difficulty in keeping the stability of gob-side entry will increase with the main roof fracturing. Therefore, the slender coal pillar is still subjected to the loading resulting from the fractured main roof as shown in Figure 2. Obviously, determining the optimum width of the slender pillar is a challenge due to the complex dynamic loading during its service life [13]. Although supplementary supports, that is, ladder beam, counter pulled bolts, and pipe umbrella, are good choices for ground control, they will lead to higher production cost.

In addition to gate pillar design, the commonly used destressing methods include drilling, blasting, and water infusion [2]. From the viewpoint of panel layout, this paper presents a new strategy for mitigating rock bursts during the deep mining of inclined longwall panels. The geological and geotechnical settings and mining conditions and circumstances leading up to coal burst events at Huafeng Coal Mine (HCM) were first analyzed. Numerical modeling, incorporating a double-yield model for gob model and calibrated parameters, was then carried out. Panel layouts employing CLTCC and a new strategy were numerically investigated to study the stress and yield zones distribution which was then verified by field observation. Conclusions are 


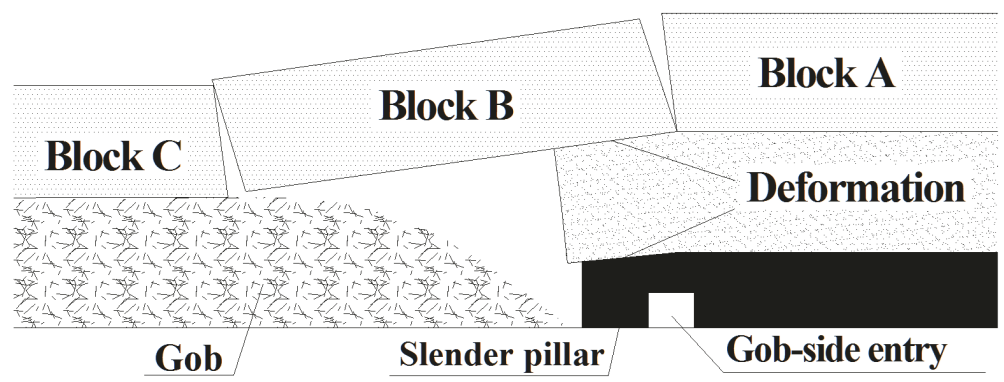

FIGURE 2: Profile of surrounding rock mass of gob-side entry.

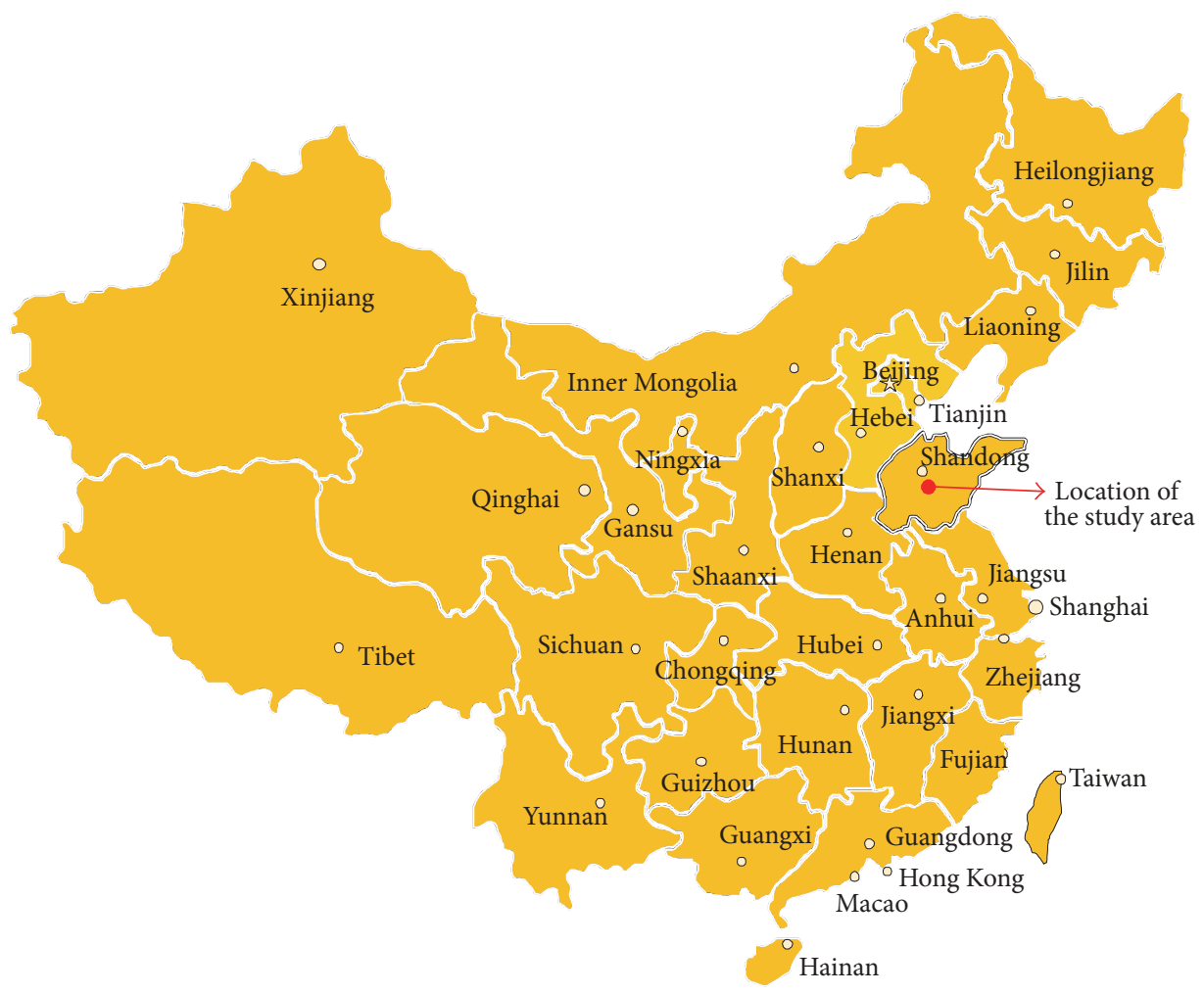

FIGURE 3: Location of the case study area.

drawn in the end according to the study of the paper. The successful experience of the new strategy at HCM can potentially be applied in similar settings.

\section{Case Study}

2.1. Geological Settings. Huafeng Coal Mine (HCM) is located in Tai'an City, Shandong Province, China (Figure 3). The coal seam being mined is \#4 coal seam. Its average thickness and dip angle were $6.2 \mathrm{~m}$ and $32^{\circ}$, respectively. The lithological characteristics of \#4 coal seam for 1410 and 1411 panels are shown in Figure 4. The immediate roof is siltstone with $2.5 \mathrm{~m}$ thickness, and the main roof is fine sandstone with $9.2 \mathrm{~m}$ thickness. The immediate floor is siltstone with a thickness of $1.7 \mathrm{~m}$, and the main floor is medium sandstone with a thickness of $4.2 \mathrm{~m}$. \#4 coal seam is relatively simple; nearly no dirt bands or partings were observed. The buried depth of the two panels varies from 840 to $1000 \mathrm{~m}$. It is $140 \mathrm{~m}$ in the dip direction and $2190 \mathrm{~m}$ in the strike direction. Due to the dip cover, the at-rest pressure coefficient of in situ stress field is near 1 . The major tectonic structures for the panels are simple. Three minor faults were revealed during the excavation of 1411 tailgate. One normal fault was discovered near the setup room; the dip angle is $60^{\circ}$; fault throw is $2.4 \mathrm{~m}$, which has an impact on retreating, so the setup room is located $20 \mathrm{~m}$ away from the fault. Two minor faults were found during the excavation of 1411 headgate. One is normal fault with only $0.7 \mathrm{~m}$ offset. The other one is adverse fault with a fault throw of $1.0 \mathrm{~m}$. Therefore, these minor faults were not likely to have significant influence on rock bursts. Fully mechanized conventional longwall top coal caving (CLTCC) method was used. The cutting height and top coal thickness were $2.4 \mathrm{~m}$ and $3.8 \mathrm{~m}$, respectively. The cutting thickness was $0.6 \mathrm{~m}$. The original longwall panel layout design is shown in Figure 5. 


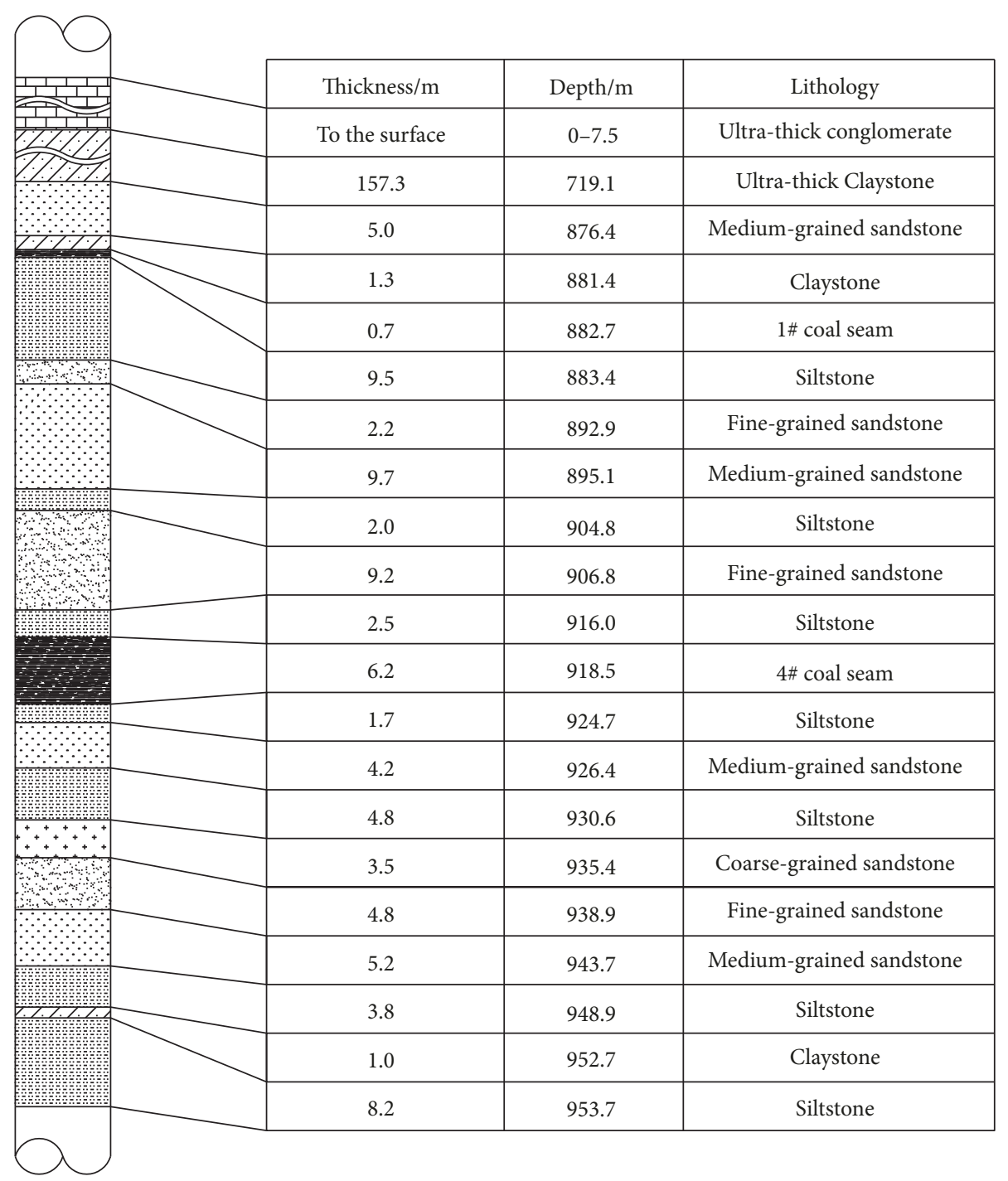

FIGURE 4: Generalized stratigraphy column of the test site.

HCM is one of the typical coal mines experiencing severe coal burst risk due to its large mining depth. The mining depth of many coal mines in China, facing similar problems, has reached more than $1000 \mathrm{~m}$ [14, 15]. From 1990 to 2006, HCM experienced over 100 coal bursts [16]. The major coal burst records are listed in Table 1.

2.2. Contributing Factors for Coal Bursts. As coal bursts frequently occur at HCM, laboratory tests were conducted on samples of \#4 coal seam and roof to investigate the intrinsic factor contributing to the occurrence of coal bursts [17]. The coal burst liability widely used in China as a standard includes the uniaxial compressive strength $\left(R_{C}\right)$, elastic strain energy index $\left(W_{E T}\right)$, bursting energy index $\left(K_{E}\right)$, and dynamic failure duration $\left(D_{T}\right)$. The classifications according to the Chinese standard $[18,19]$ are listed in Table 2 . The indexes were measured through coal samples obtained from the 1410 and 1411 panels. These four indexes are all determined by uniaxial compression tests and can be calculated easily. The two indexes $R_{C}$ and $D_{T}$ are good choices to evaluate this intrinsic proneness. For the indexes $W_{E T}$ and $K_{E}, W_{E T}$ focuses on the capacity of rock to absorb the external inputs of energy before it achieves peak strength, and $K_{E}$ considers the accumulated elastic energy before peak strength and the released energy after the peak strength is achieved. These two indexes can determine the ability of energy accumulating and energy releasing. Although some drawbacks exist, these indexes now play an important role in evaluating the risk of rock burst in coal seams. In general, they reflect the intrinsic burst proneness and assess the energy accumulation capacity of coal [18, 19]. The test results are listed in Table 3. The test results show that coal seam has high bursting liability and the immediate roof has medium bursting liability.

In addition to intrinsic contributing factors, burst-prone geology is an external contributing factor that may triggers coal bursts. One important external factor was deep cover [3]. The buried depth of 1410 panel was over $800 \mathrm{~m}$. The buried depth of 1412 panel almost reaches $1050 \mathrm{~m}$ with vertical stress 


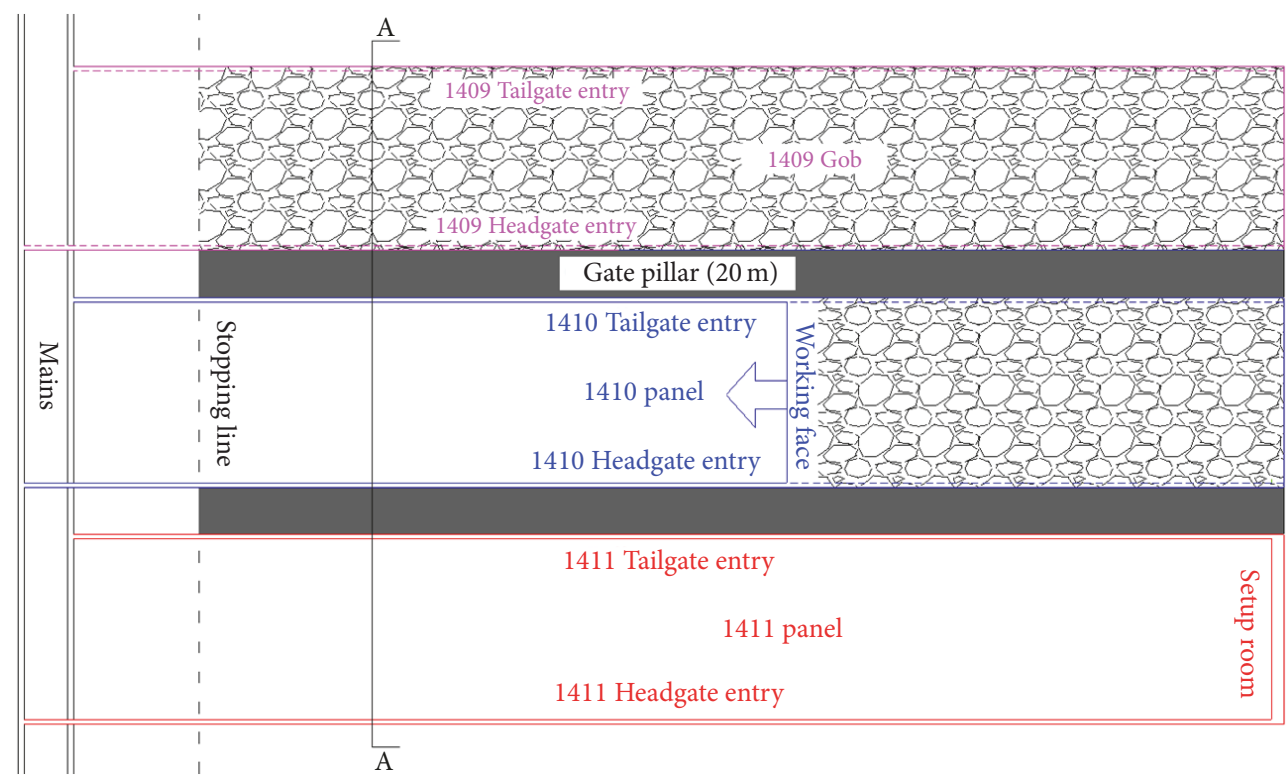

(a)

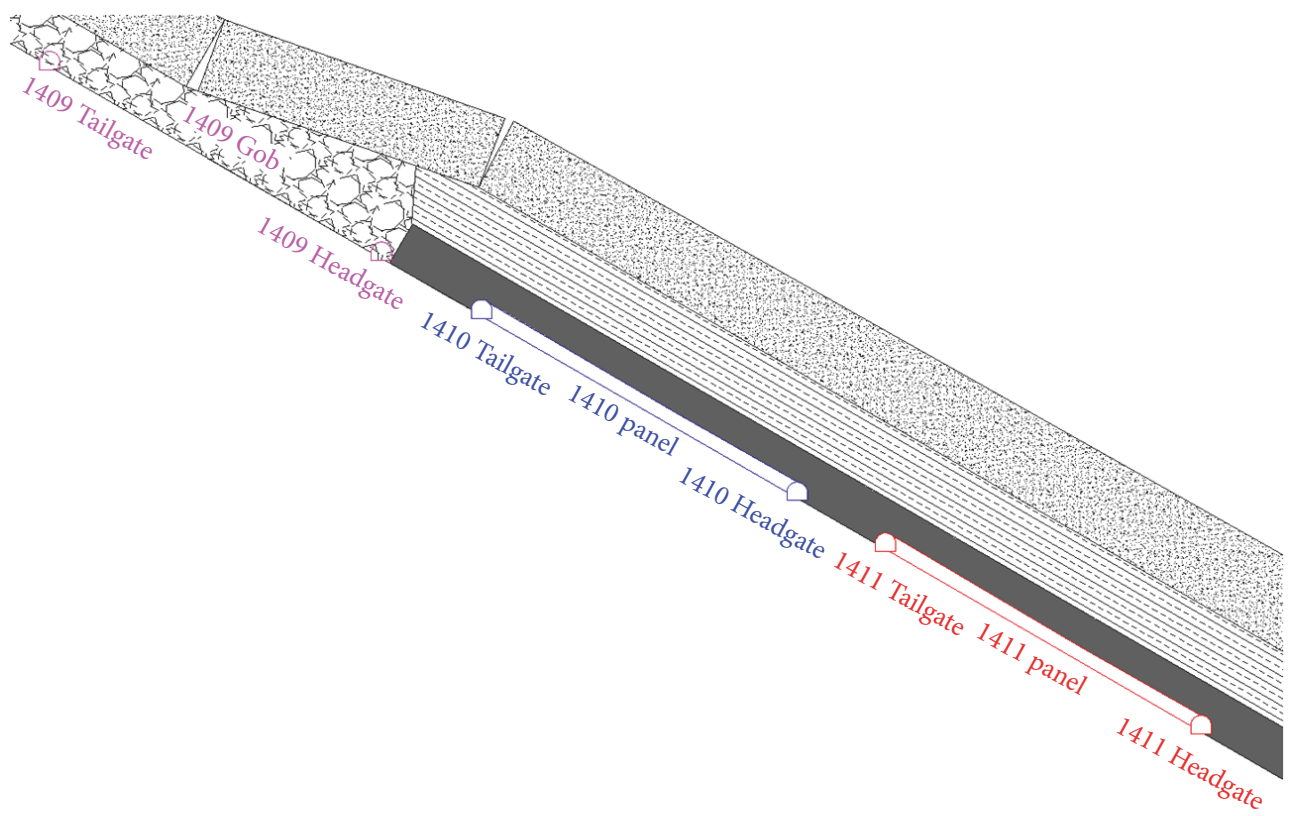

(b)

Figure 5: Original layout of 1409, 1410, and 1411 panels (not to scale). (a) Plan view, (b) A-A section view.

of $50 \mathrm{MPa}$. In addition, the in situ stress measurement showed that the maximum horizontal stress was $33-42 \mathrm{MPa}$, which is bigger than the uniaxial compressive strength of coal seam.

Other factors were overlying ultrathick claystone strata $(120-190 \mathrm{~m})$ and conglomerate strata $(500-750 \mathrm{~m})$. With the extraction of coal seam, overhanging of these strata above the coal seam or interblock and bridging of blocks of the competent strata led to an increase in abutment stresses within the rock mass around the mined-out area. When these strata fractured, rotated, and caved in, dynamic loading was brought about and bursting risk increased correspondingly. What is more, discontinuous or stepped subsidence occurred due to the fracture of ultrathick strata, which was corroborated by field observation as shown in Figure 6, and the corresponding mechanism is illustrated in Figure 7. Limit line is the line connecting panel boundary and the cracks that occurred on the ground surface.

Faults are also a factor that led to coal bursts as sliding of rock mass on two sides of a fault may cause sudden release of a large amount of energy [20]. A fault was encountered when 


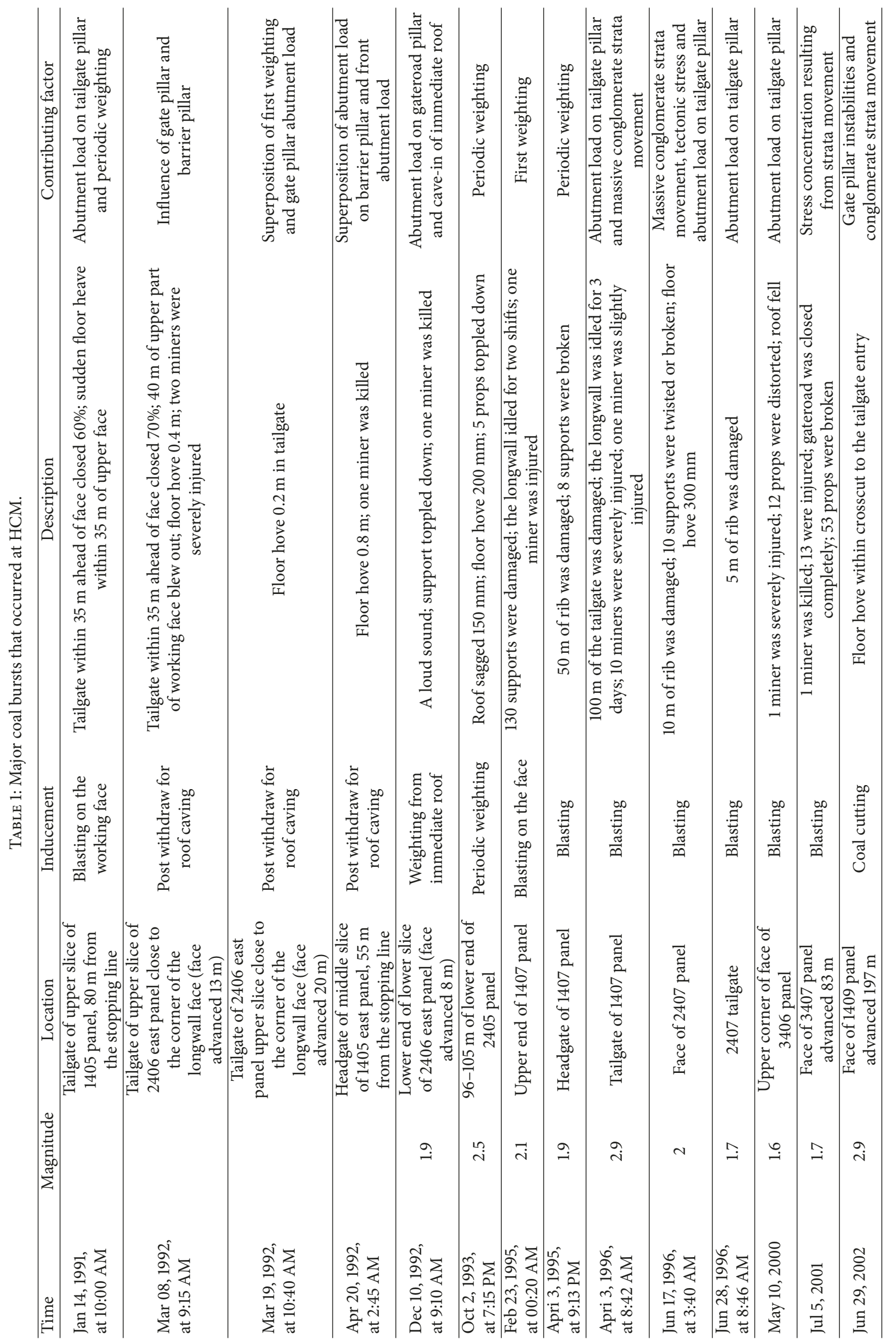




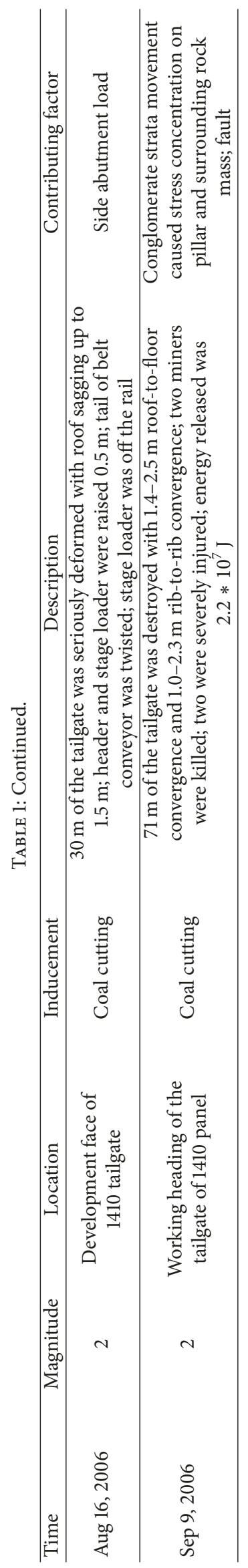


TABLE 2: Classification of the bursting proneness of coal and rock.

\begin{tabular}{lcccc}
\hline Type & Indicator & $\begin{array}{c}\text { High } \\
\text { bursting }\end{array}$ & $\begin{array}{c}\text { Medium } \\
\text { bursting }\end{array}$ & No bursting \\
\hline \multirow{3}{*}{ Coal } & Duration of dynamic failure, $D_{T}$ & $<50$ & $50-500$ & $>500$ \\
& Elastic strain energy index, $W_{E T}$ & $>5$ & $2-5$ & $<2$ \\
& Bursting energy index, $K_{E}$ & $>5$ & $1.5-5$ & $<1.5$ \\
\hline Roof rock & Bending energy index $(\mathrm{kJ})$ & $>120$ & $10-120$ & $<15$ \\
\hline
\end{tabular}

TABLE 3: Testing results of intrinsic bursting proneness.

\begin{tabular}{lccc}
\hline & 4\# coal seam & Immediate roof \\
Duration of dynamic fracture $(\mathrm{ms})$ & Elastic strain energy index & Bursting energy index & \multicolumn{2}{c}{\begin{tabular}{c} 
Bending energy index \\
\hline 33.3
\end{tabular}} & 13.05 & 5.1 & 49.5 \\
& High bursting & Medium bursting \\
\hline
\end{tabular}

mining 1410 panel. It was oriented west with a fault throw of $3.5 \mathrm{~m}$. However, practice suggested that the fault did not have a big impact on mining of 1410 .

Despite these factors, the most significant one was improper panel layout [21]. In the past, the coal mine used CLTCC with a gate pillar of $20 \mathrm{~m}$ between adjacent CLTCC panels. This system led to severe stress concentration on gate pillar [22, 23]. Tailgates next to the gob, in particular, were subject to very high side abutment load and majority of coal bursts occurred in tailgates during both development and panel retreating [24]. As we can see from Table 1, almost all major coal bursts occurred within the tailgate. If other factors are key factors, the headgate should have experienced severe coal burst problems as well. This corroborates the statement that CLTCC panel layout is the most significant factor. $0-80 \mathrm{~m}$ ahead of working face in tailgates and at the corner of the longwall face underwent superposition of front and side abutment loads; damage at these locations resulting from bursts was therefore the most serious as shown in Figure 8.

Laboratory tests, in situ measurements, and field observation indicated that the past panel layout was not suitable for burst prevention. As stated earlier, the improper layout is the most significant controlling factor since it has been reflected through the major coal bursts that occurred at HCM in the past as listed in Table 1, while no coal bursts occurred after the new strategy was employed, which corroborates the statement that layout in the past is improper. A more rational panel layout is a must.

2.3. Overview of the New Strategy: Longwall Mining with Split-Level Gateroads (LMSG). After extraction of 1409 panel, the new strategy, that is, longwall mining with split-level gateroads (LMSG), was employed for subsequent panels at HCM. LMSG is a longwall mining layout approach that was proposed first by China University of Mining and Technology (CUMTB) $[8,18,19]$. LMSG locates gateroads on either end of a panel at different heights within a coal seam so that adjacent panels overlap end to end and the tailgate of the adjacent next panel can be located below the headgate entry of the previous panel or may be offset horizontally with respect to it.
Figure 9 shows a typical two-entry LMSG layout. The tailgate is driven right above the floor level while the headgate is driven right below the roof with gradually transforming section on one end of the panel. This part is transformed incrementally by adjusting the inclination of each section of the armored face conveyor (AFC), shields, and other production machines. The length of each AFC section is typically $1.5 \mathrm{~m}$ and change of inclination of each AFC with respect to the adjoining ones is less than $3^{\circ}$. Figure 10 shows $3 \mathrm{D}$ views of shield layout for one LMSG panel. A small pillar with a triangular $x$-section is left unmined between adjacent LMSG panels. And operation units in LMSG are also different from conventional systems which are discussed in detail by Zhao (2017) and Wang (2018).

LMSG was adopted at HCM in 2006 to deal with coal bursts which also increased stability of mining equipment at working face and coal recovery. The panel layout is shown in Figure 11 .

\section{Numerical Modeling}

3.1. Model Development and Simulation Steps. To investigate the stress distribution and yield zone development within surrounding rock mass, numerical modeling using FLAC3D code was first carried out. Figure 12 shows FLAC3D model developed based on Figures 4 and 11 without excessive complexity and computational burden. The dimension of the model was $500 \mathrm{~m} \times 300 \mathrm{~m} \times 400 \mathrm{~m}$. A significant distance to the lateral boundaries and the bottom boundary was also required to minimize model boundary effects. Model zone sizes were graded from small around material boundaries to large at the center of a material domain. Suitably fine zone resolution in the vicinity of coal seam unit and gateroads was generated for accurate prediction of progressive yielding and deformation. A uniform stress of $17.5 \mathrm{MPa}$ was applied to the top of the model corresponding to $700 \mathrm{~m}$ of overburden strata by assuming the overlying unit weight was $0.025 \mathrm{MN} / \mathrm{m}^{3}$ and gravity force was applied [25]. The side boundaries were roller-constrained and the bottom boundary was fixed both horizontally and vertically. Based on premining stress 

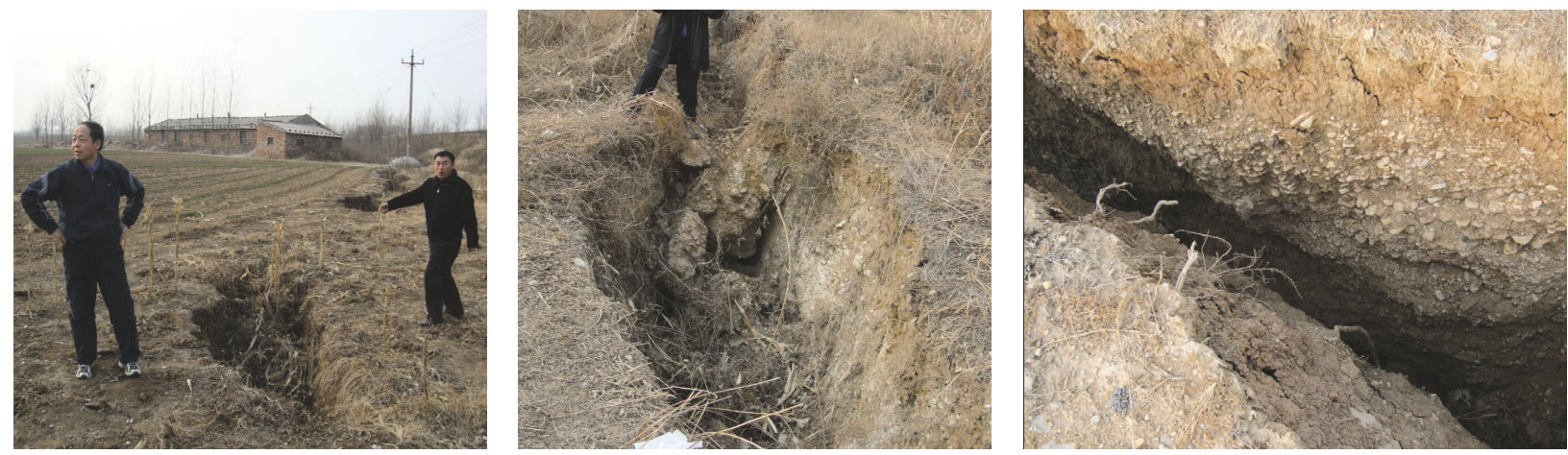

FIGURE 6: Field observation.

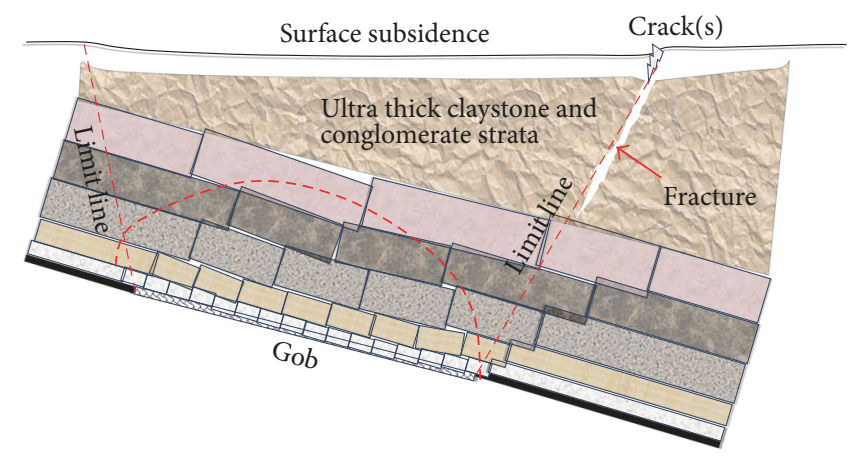

FIGURE 7: Schematic of discontinuous or stepped subsidence under the influence of ultrathick conglomerate strata.

measurements in the mine, a ratio of horizontal to vertical stresses $(K)$ of 1.8 in both the model's in-plane and out-ofplane directions was input. In addition, discontinuous model interfaces, representing bedding planes, capable of yielding and separating, were built into the model at the contact of each stratum using FLAC interface logic. The methods and parameters proposed by Wang et al. [26] for interfaces were employed. Simulation was performed in six stages, that is, stage I: loading the model to premining state of stress without any excavation; stage II: only two development entries of the 1409 panel were excavated; stage III: the 1409 panel was excavated; stage IV: two development entries of the 1410 panel were excavated; stage V: the 1410 panel was excavated; stage VI: tailgate entry of the 1411 panel was excavated.

3.2. Development of Rock Mass Engineering Parameters. Constitutive model and parameters used in numerical modeling have significant influences on the reliability of simulation results. The widely used Generalized Hoek-Brown (GHB) failure criterion was adopted for simulation in this paper [27]. The rock mass engineering parameters were developed based on laboratory test and estimated GSI values; RocData software was used to assess the effect of engineering properties on failure behavior [28]. The GHB rock mass engineering properties used for numerical modeling are given in Table 4 .

Caved rock fragments are compacted until an equilibrium is reached when no roof strata subsidence occurs. During the gob consolidation process, the stress-strain behavior of gob satisfies Salamon's equation [29] which was proved by laboratory test performed by Pappas and Mark [30]. With the consolidation of gob, the load borne by the gob increases with the reduction of abutment load acting on surrounding rock mass correspondingly [31, 32]. Therefore, gob response should be taken into account in numerical analysis. Built-in double-yield constitutive model in FLAC $^{3 \mathrm{D}}$ was used to simulate the gob in this study [33] (refer to Zhang et al. [34] for further details).

Cap pressure [33] for double-yield model is estimated by Salamon's equation which is expressed by

$$
\sigma=\frac{E_{0} \varepsilon}{1-\left(\varepsilon / \varepsilon_{m}\right)},
$$

where $\sigma$ is the stress applied to the gob materials, $\varepsilon$ is the volumetric strain under the applied stress, $E_{0}$ is the initial tangential modulus, $\varepsilon_{m}$ is the maximum volumetric strain, and [31]

$$
\begin{aligned}
E_{0} & =\frac{1.039 \sigma_{c}^{1.042}}{b^{7.7}} \\
\varepsilon_{m} & =\frac{b-1}{b},
\end{aligned}
$$

where $\sigma_{c}$ is the compressive strength of the rock pieces, $b$ is the bulking factor, and [35]

$$
b=\frac{H_{c}+m}{H_{c}},
$$



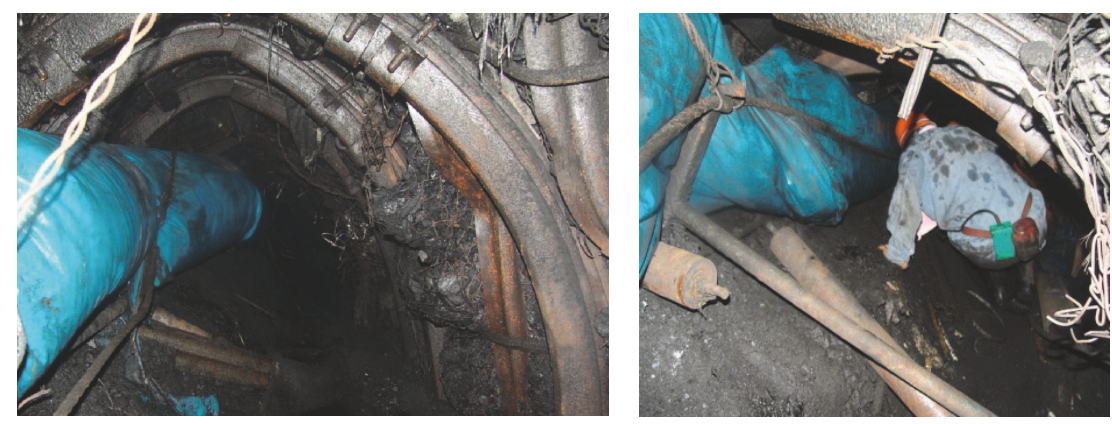

Figure 8: Damage of 1410 tailgate.

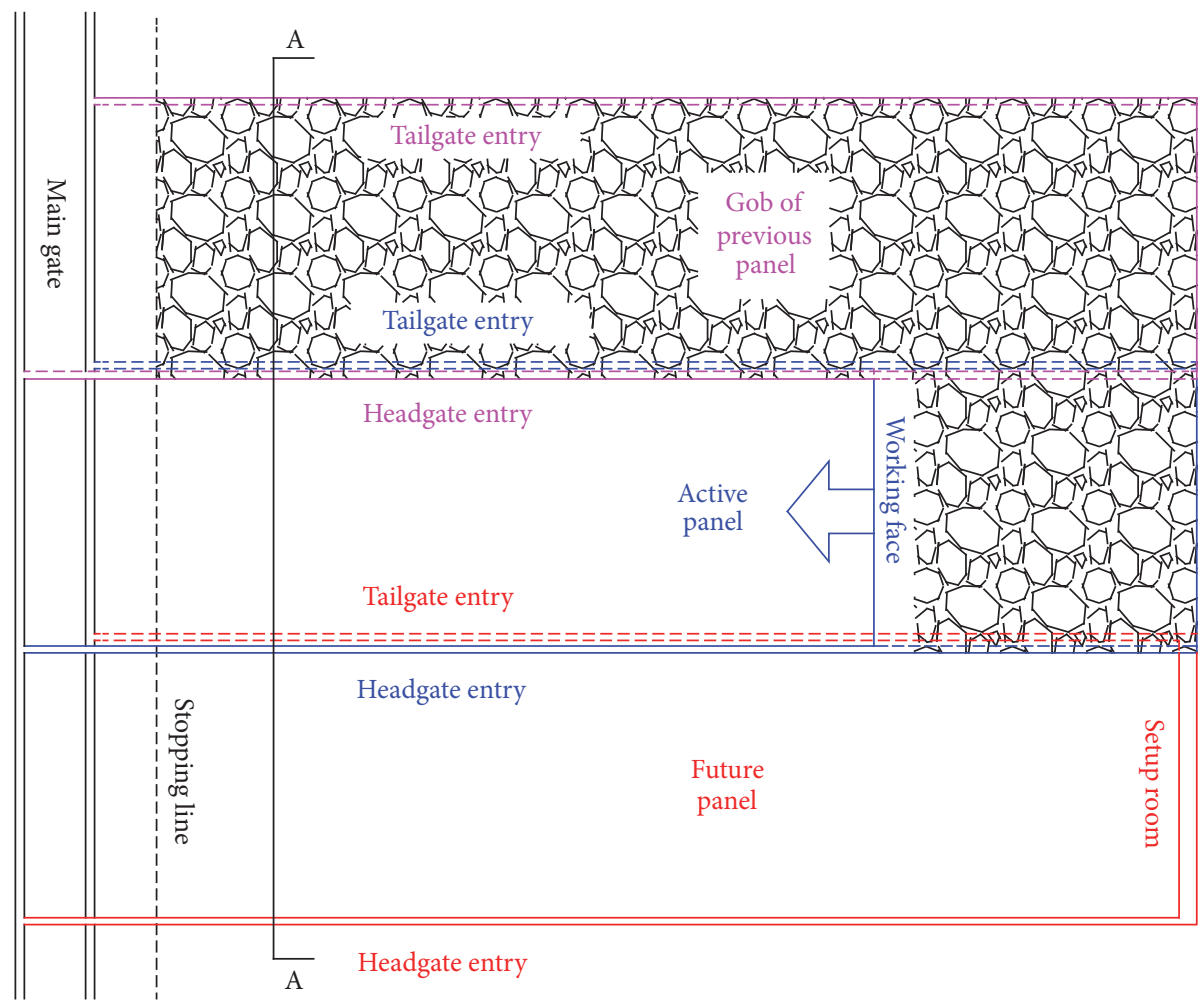

(a)

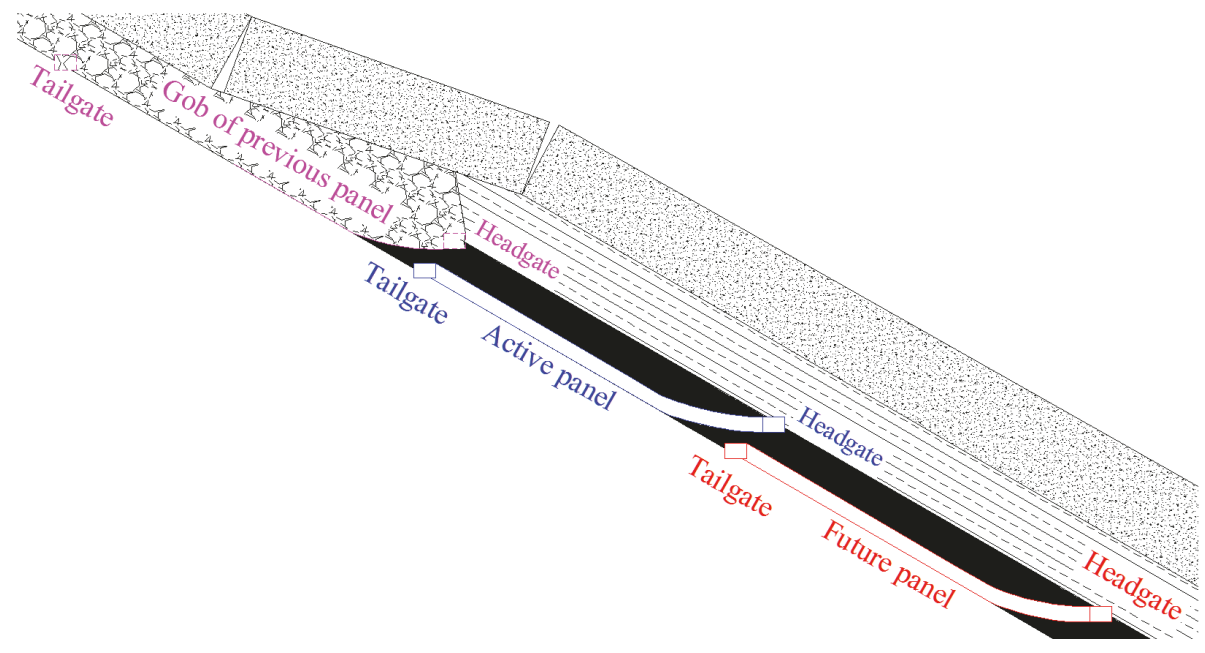

(b)

FIGURE 9: Typical longwall mining with split-level gateroads top coal caving mining layouts (not to scale). (a) Plan view of LMSG panel layout. (b) Section view of LMSG layout in inclined coal seam. 


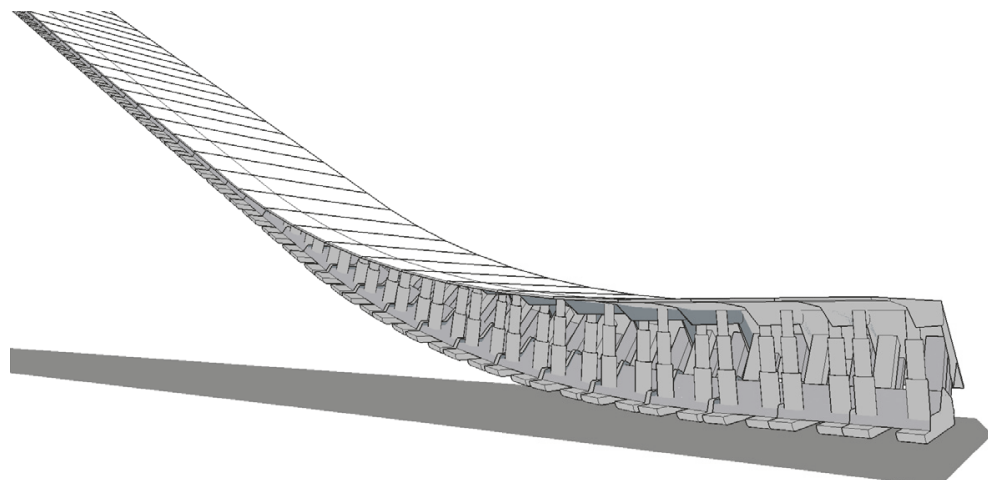

FIGURE 10: 3D views of shield layout for one LMSG panel.

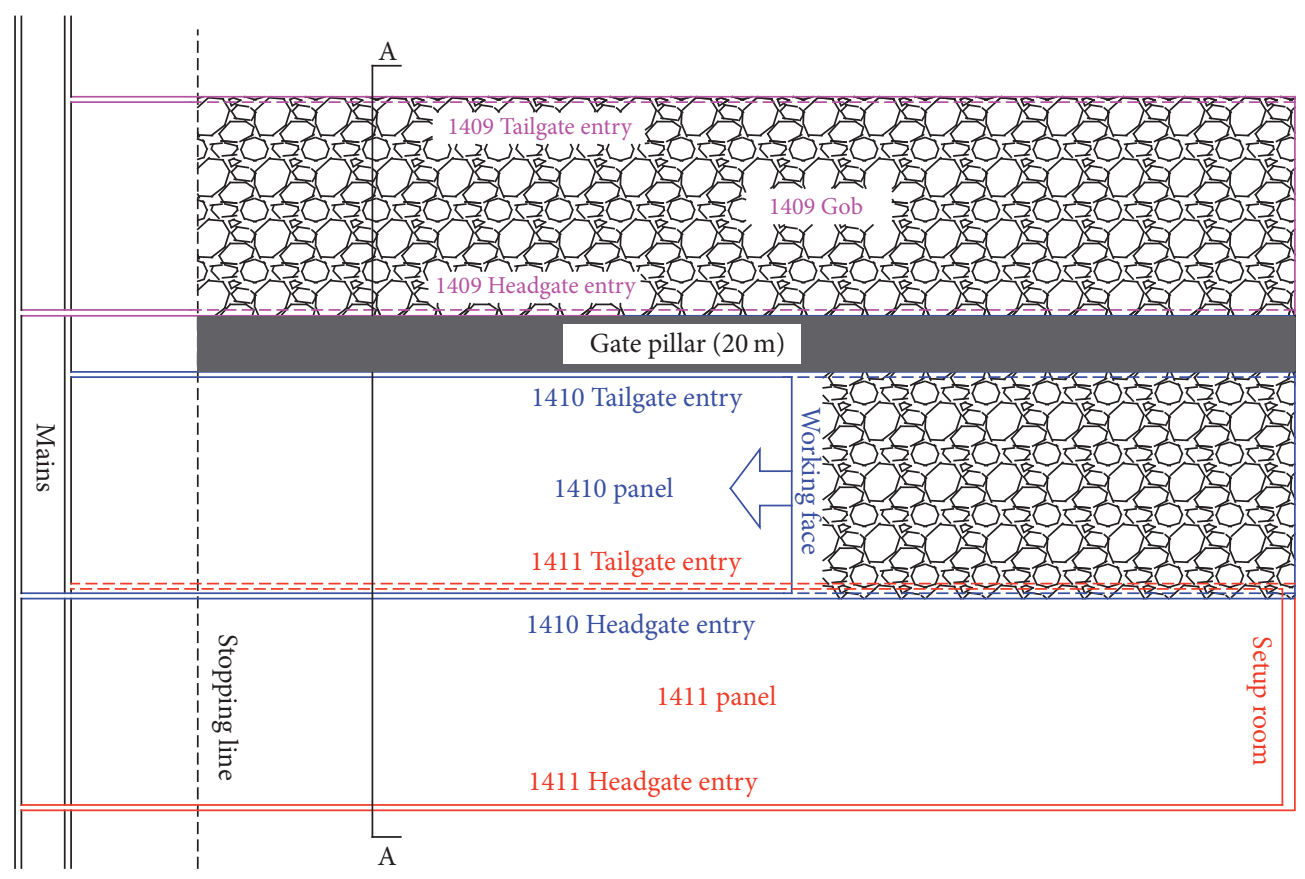

(a)

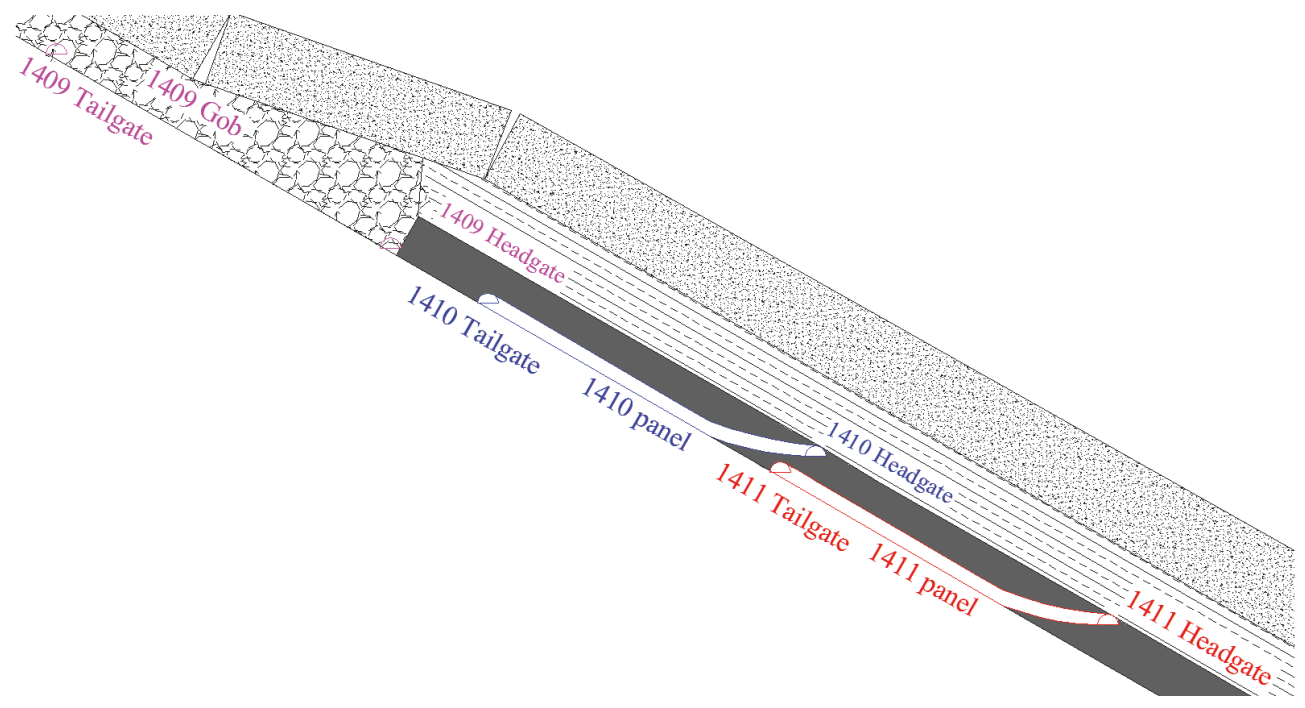

(b)

FIGURE 11: LMSG layout of 1409, 1410, and 1411 panel (not to scale). (a) Plan view, (b) A-A section view. 


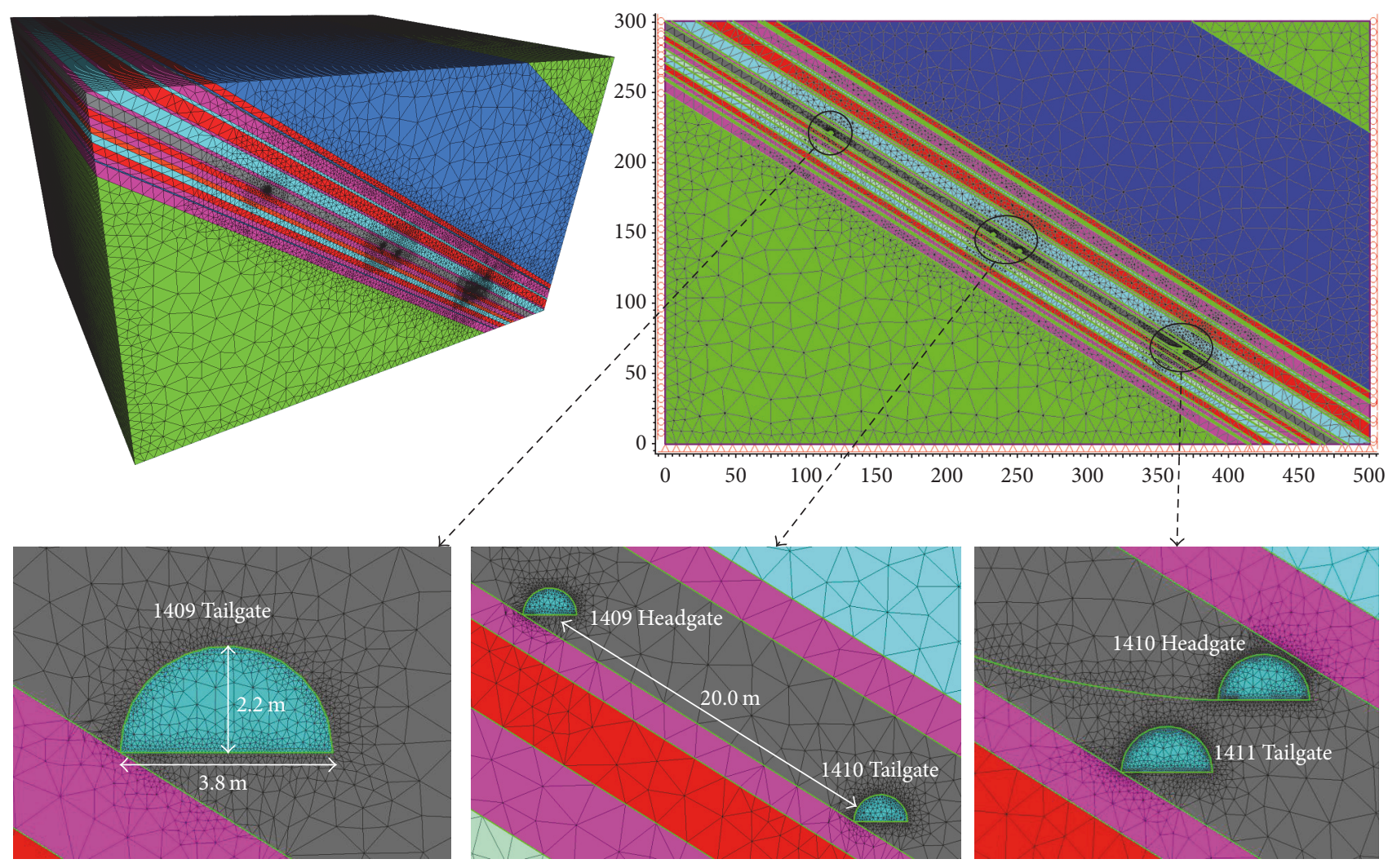

Figure 12: FLAC3D mesh.

where $H_{c}$ is the height of caved zone and $m$ is the mining height.

According to cross-measure drill holes during mining of 1409 panel, the height of the caved zone was about $25.6 \mathrm{~m}$ above the coal seam reaching $9.5 \mathrm{~m}$ thick siltstone stratum. Hence, the bulking factor, maximum strain, and the initial modulus of the gob materials can be calculated as 1.242, $0.195 \mathrm{~m} / \mathrm{m}$, and $67.7 \mathrm{MPa}$, respectively. Cap pressure for the double-yield model is given in Table 5 and is expressed by

$$
\sigma=\frac{67.7 \varepsilon}{1-5.13 \varepsilon}
$$

In order to obtain the parameters for gob and make sure that the stress-strain relationship agrees with (4), a simple model with dimensions $1 \mathrm{~m}$ (length) $\times 1 \mathrm{~m}$ (width) $\times 2 \mathrm{~m}$ (height) was built (in order to display stress and strain contours). Loading was simulated by applying a velocity on the top surface with bottom surface fixed vertically and four side surfaces fixed horizontally. The input parameters were fitted by iterative changes in the bulk and shear modulus, angle of dilation, angle of friction, and density of gob material. By trial and error, the final properties are given in Table 6. The volumetric strain, vertical stress contours, and stress-strain matching curves are given in Figure 13. This shows that numerically obtained data agrees very well with Salamon's equation.

3.3. Validation for the Obtained Parameters. The results were compared with field observation to validate the reliability of the parameters. As discussed earlier, the pressures distributed within rock mass and gob interacted, and the increase of gob pressure results in the reduction of abutment stress. Therefore, the reliability of the parameters that determine numerical modeling output can be validated against the measurement data of abutment pressure.

The premining stress was approximately $21 \mathrm{MPa}$ because 1410 tailgate was $840 \mathrm{~m}$ deep. The measured data was obtained through stress meters (a total of five) installed in stressmonitoring boreholes in 1410 tailgate surrounding rock mass including gate pillar and 1410 panel rib. For field monitoring data, the stress-monitoring station was installed $500 \mathrm{~m}$ behind 1409 working face where strata movement had ceased and stress distribution within surrounding rock mass became stable. Figure 14 shows a comparison between the measured and simulated side abutment pressures in stage IV. Simulated result was in close agreement with the field measurement data. The input parameters were therefore validated.

3.4. Summary of Modeling Results. The modeling results and field measurement data (Figure 14) indicated that the maximum side abutment stress reached $42 \mathrm{MPa}$, resulting in adverse stress environment for 1410 tailgate, and coal burst risk was very high. Modeling results of the key stages, that is, stage III and stage IV, are given in Figures 15 and 16.

Figure 15 shows that the limit line was coincident with the field observation (Figure 6). Field observation demonstrated that the angles formed by limit line and the coal seam 


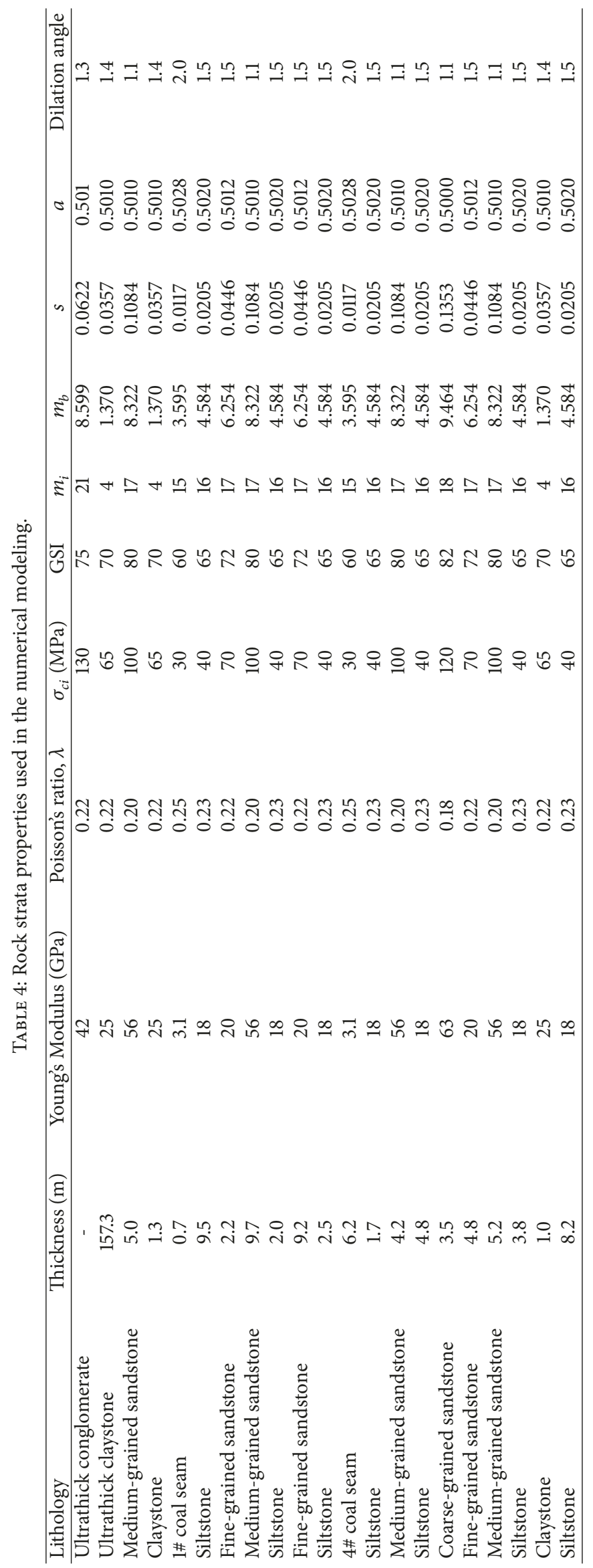




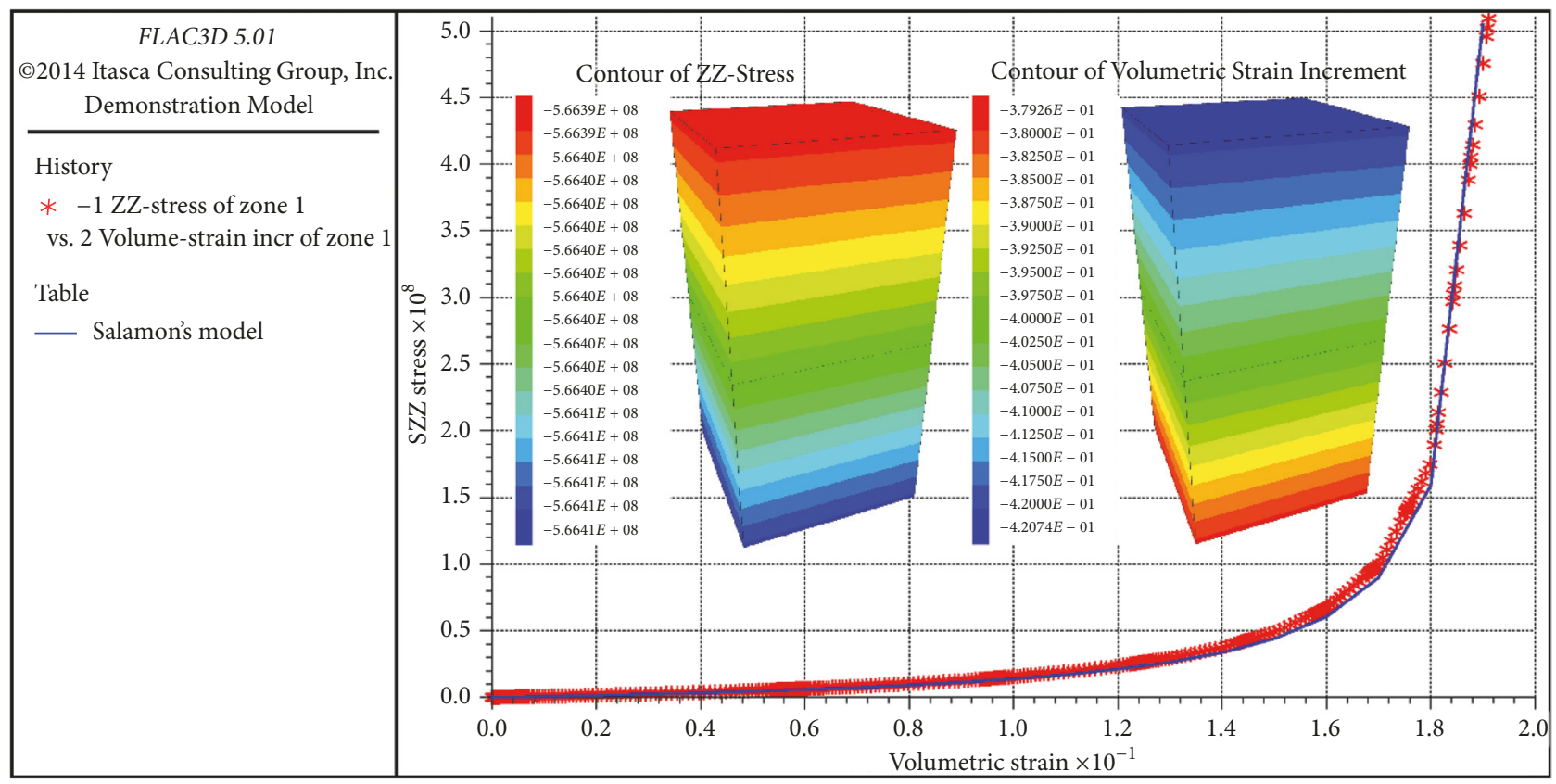

FIGURE 13: The volumetric strain, vertical stress contours, and stress-strain matching curves.

TABLE 5: Cap pressures for the double yield model.

\begin{tabular}{lc}
\hline Strain $(\mathrm{m} / \mathrm{m})$ & Stress $(\mathrm{MPa})$ \\
\hline 0.00 & 0.00 \\
0.01 & 0.71 \\
0.02 & 1.51 \\
0.03 & 2.40 \\
0.04 & 3.41 \\
0.05 & 4.55 \\
0.06 & 5.87 \\
0.07 & 7.39 \\
0.08 & 9.18 \\
0.09 & 11.32 \\
0.10 & 13.90 \\
0.11 & 17.09 \\
0.12 & 21.13 \\
0.13 & 26.41 \\
0.14 & 33.61 \\
0.15 & 44.02 \\
0.16 & 60.39 \\
0.17 & 89.86 \\
0.18 & 158.71 \\
0.19 & 504.69 \\
\hline
\end{tabular}

floor line were $43.4^{\circ}$ (upper) and $88.2^{\circ}$ (lower), respectively. Numerical modeling shows that the angles were 42.5 (upper) and $87.9^{\circ}$ which agreed very well with field observation. This also confirms the reliability of the parameters used in the simulation.

After extraction of 1410 panel, although the remaining gate pillar was in yield state, the stress was still very high with maximum value of $45.5 \mathrm{MPa}$, higher than $42 \mathrm{MPa}$ before extraction. The abutment stress of 1411 panel was about $39 \mathrm{MPa}$. However, 1411 tailgate was located below the 1410 gob where it was destressed, and the abutment load did not influence 1411 tailgate. This shows that the stress around the 1411 tailgate is much lower than premining stress, and the stress concentration is to the right of the 1411 tailgate and within the solid coal ahead of the working face of the active panel. Therefore, 1411 tailgate is subjected to little influence of front and side abutment loads. As Li (2016) noted, LMSG reduces the static stress within the coal-rock mass surrounding the 1411 tailgate and attenuates dynamic stresses transmitted to the tailgate which is favorable to rock burst control for the tailgate.

\section{Field Measurement}

As the roof of 1411 tailgate was $2 \mathrm{~m}$ thick coal that was sort of yielded and cracked, it would be inappropriate to use bolts for roof support. Therefore, No. 36 U-type yielding steel members spaced at $1000 \mathrm{~mm}$ were adopted for global support of 1411 tailgate accompanied with wire mesh on the top and bolts for rib reinforcement. Grouting or a thin shotcrete layer was also supplemented to overcome air-leakage disadvantage of the tailgate $[8,9]$. Figure 17 is the 1411 tailgate profile ahead of longwall face using such measure. In some cases employing LMSG, geosynthetic materials (such as membranes which are $2-3 \mathrm{RMB} / \mathrm{m}^{2}$ ) were used to isolate the tailgate from the gob. During the panel retreat, no seismic events larger than 1.5 magnitude or bursts were recorded.

The deformation of tailgates of the 1410 and 1411 panels was monitored during gate driving and panel retreat. The convergence of the tailgates was monitored using crossmonitoring method and a flexible tape as shown in Figure 18 [10]. Differences of "AB" and "CD" with respect to their 


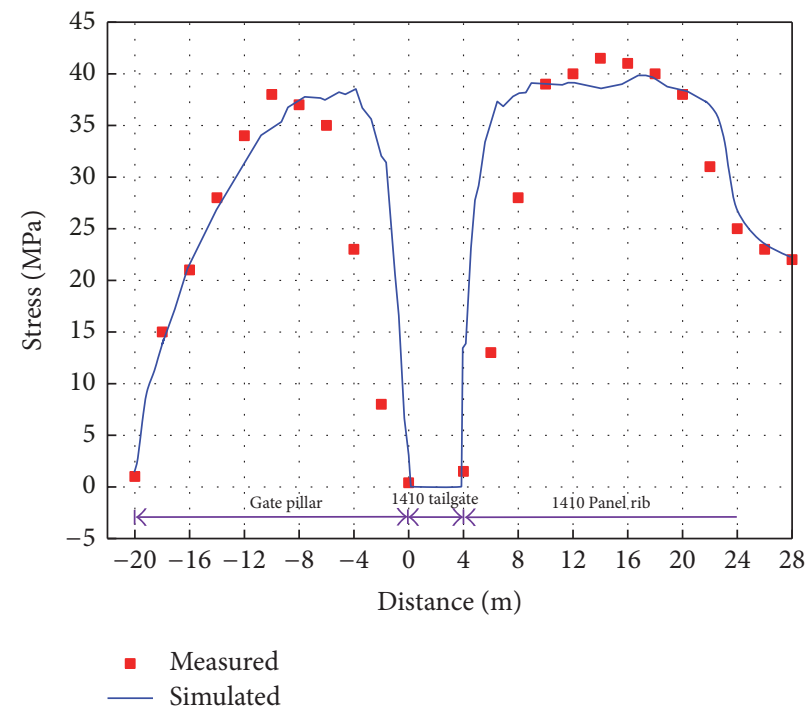

FIGURE 14: Side abutment stress distribution of numerical simulation and field measurement.

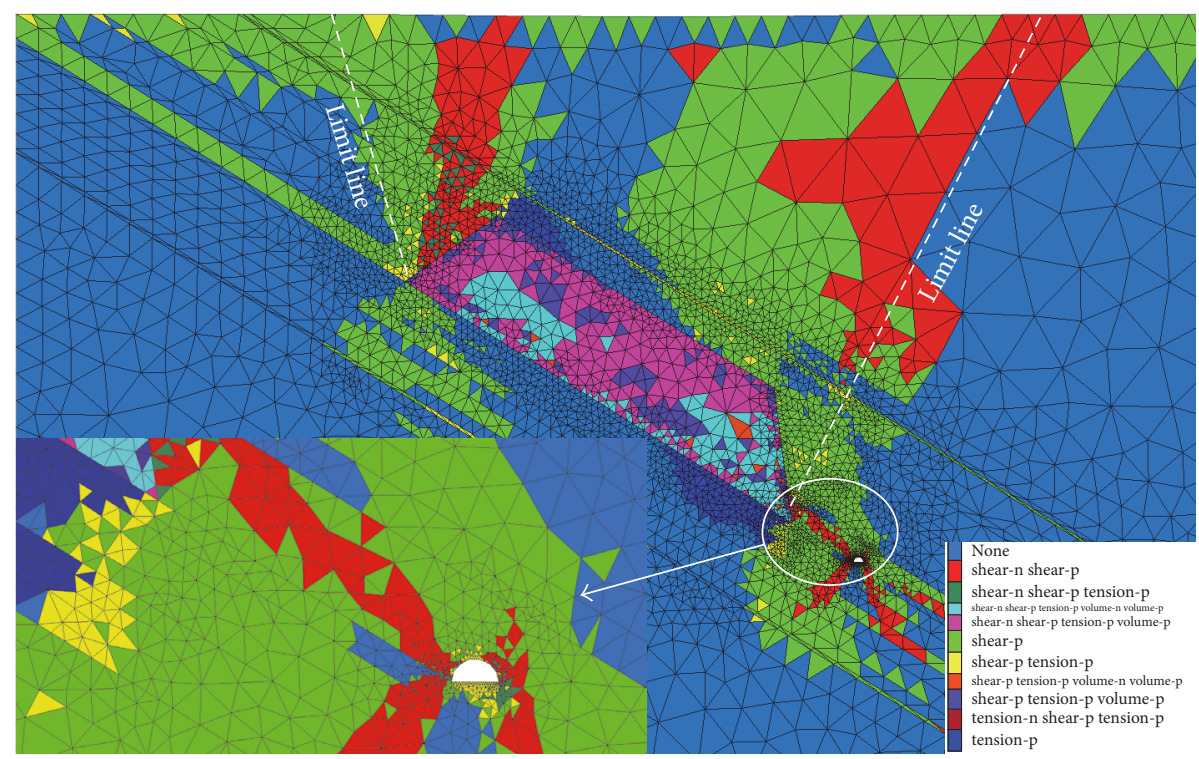

FIGURE 15: Yield elements after extraction of 1409 panel.

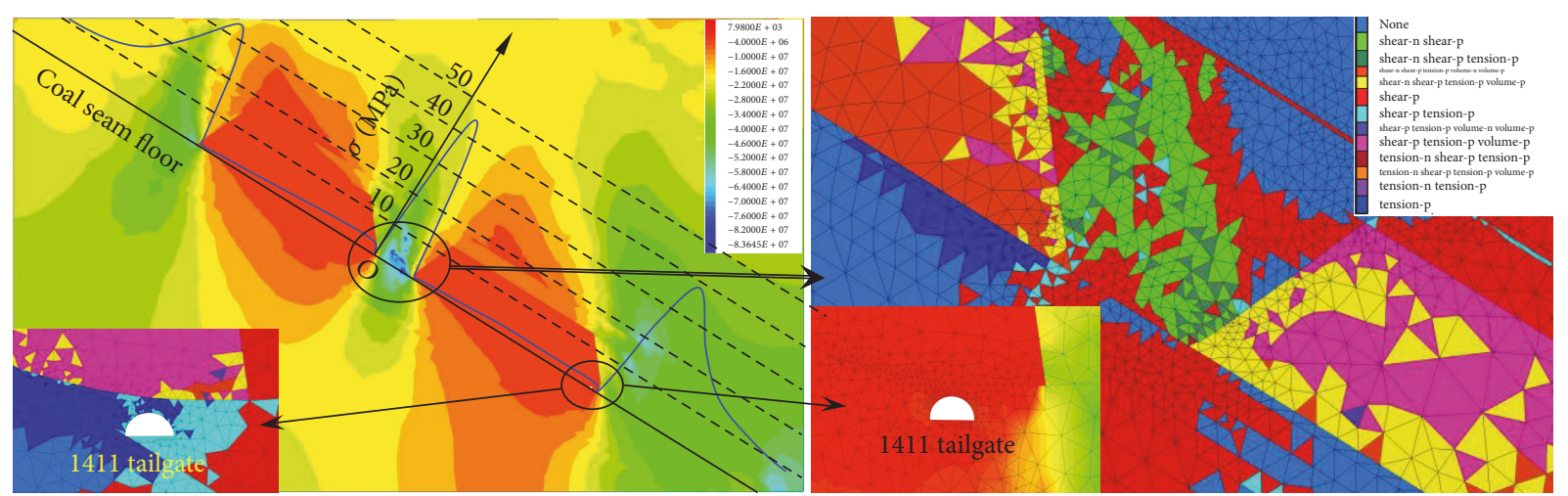

FIGURE 16: Stress distribution and yield elements after extraction of 1410 panel and development of 1411 tailgate. 
TABLE 6: Parameters for gob material.

\begin{tabular}{lcccc}
\hline Density $\left(\mathrm{kg} / \mathrm{m}^{3}\right)$ & Bulk modulus $(\mathrm{GPa})$ & Shear modulus $(\mathrm{GPa})$ & Friction $\left(^{\circ}\right)$ & Dilation $\left(^{\circ}\right)$ \\
\hline 1700 & 28 & 19 & 13 & 7.3 \\
\hline
\end{tabular}

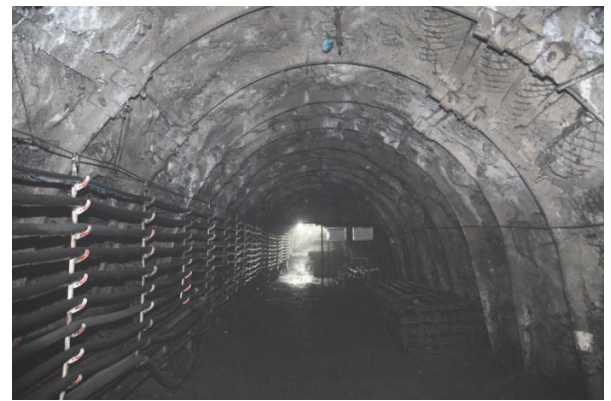

FIGURE 17: Tailgate profile ahead of longwall face.

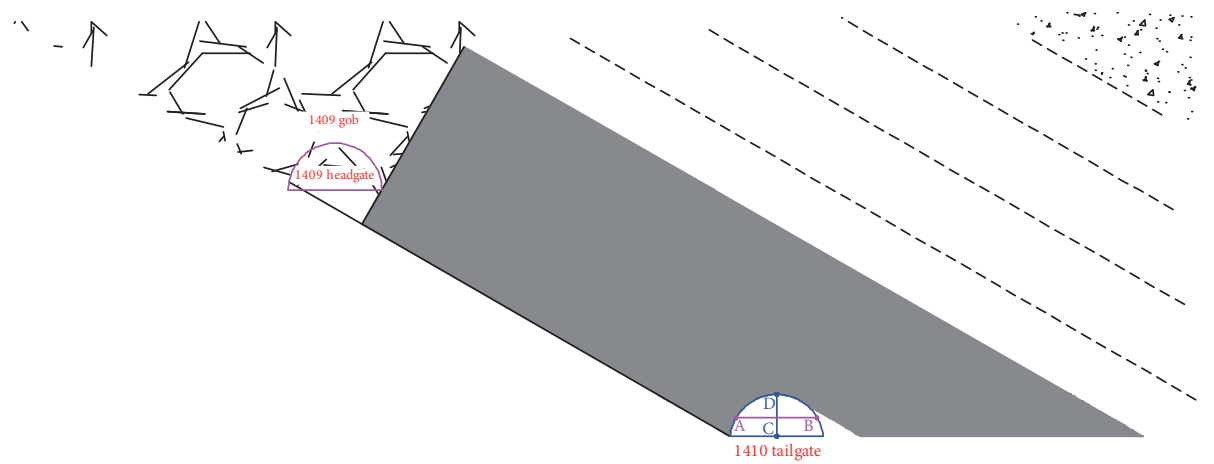

(a)

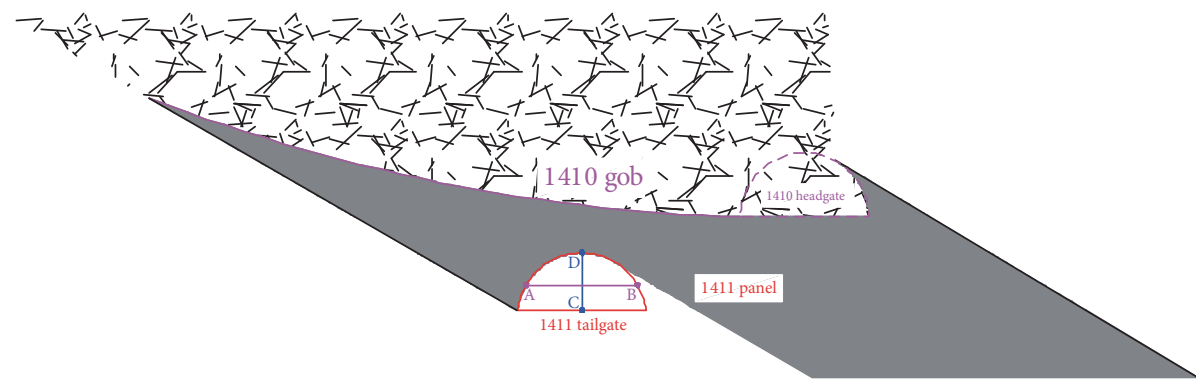

(b)

FIGURE 18: Cross-monitoring method. (a) Monitoring layout in 1410 tailgate. (b) Monitoring layout in 1411 tailgate.

initial values represented rib-to-rib convergence and roofto-floor convergence, respectively. The data obtained are plotted in Figure 19. The result shows that convergence of 1411 tailgate is much smaller than that of 1410 tailgate. The roof-to-floor and rib-to-rib convergences of 1410 tailgate were $172 \mathrm{~mm}$ and $92 \mathrm{~mm}$, respectively, while those of 1411 tailgate were only $113 \mathrm{~mm}$ and $69 \mathrm{~mm}$. During panel retreating, the convergences of the tailgate were still increasing far ahead of the working face with respect to the convergences after 90 days of development of the tailgates. However, the convergence of 1411 tailgate close to the working face did not increase much compared with that of 1410 tailgate. This demonstrated that LMSG dealt with not only coal bursts, but also large deformation problems in conventional mining layout with reduction of other ground control problems. Field measurement results confirmed the effectiveness of LMSG layout approach and the corresponding support system.

\section{Conclusions}

This paper has presented a coal burst mitigation strategy, that is, longwall mining with split-level gateroads (LMSG) for gateroad during deep mining of deep inclined longwall panels at HCM. Gateroads on either end of a LMSG panel are located 


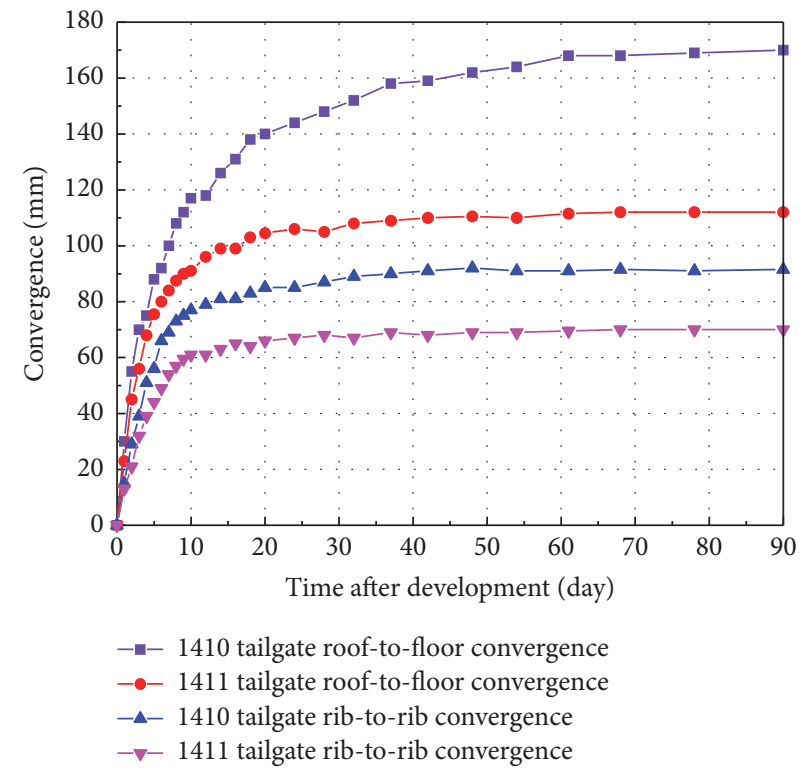

(a)

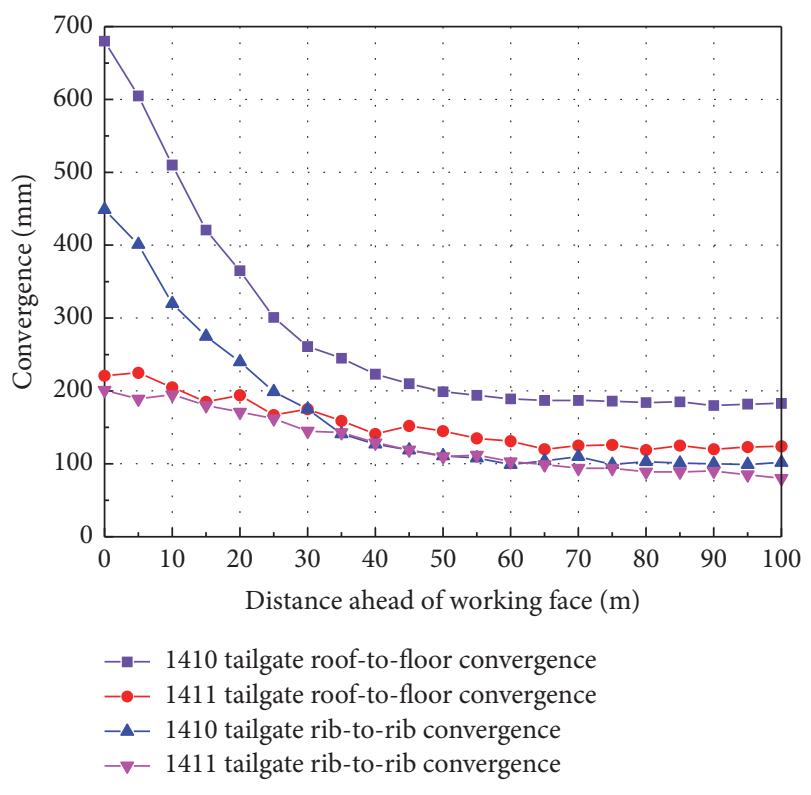

(b)

FIGURE 19: Field measurement of convergences of 1410 and 1411 tailgates. (a) Convergences of 1410 and 1411 tailgates against time after development. (b) Convergences of 1410 and 1411 tailgates against distance ahead of working face.

at different heights within a coal seam, adjacent LMSG panels overlap end to end, and the tailgate of the adjacent next LMSG panel can be located below the headgate entry of the previous LMSG panel or may be offset horizontally with respect to it.

Laboratory tests, in situ measurement, and field observation demonstrated that the coal burst liability of the coal seam and immediate roof stratum, deep cover, overlying ultrathick (500-800 m) conglomerate strata, faults, and, most importantly, improper panel layout are contributing factors leading to coal bursts. The numerical modeling results indicated that standard LTCC system gave rise to high ground pressure for the tailgate entries next to the gob, while LMSG tailgate entry below the gob edge was in a destressed environment and coal bursts are significantly mitigated. Field monitoring of LMSG at HCM demonstrates that LMSG effectively dealt with coal burst problems during mining of deep inclined longwall panels with reduced incidence of ground control problems, and sliding of mining equipment downhill was significantly reduced along with increased recovery. The technology has the potential to be utilized in other coal mines all over the world with similar geologic conditions.

\section{Conflicts of Interest}

The authors declare no conflicts of interest regarding the publication of this paper.

\section{Acknowledgments}

This work was supported by the National Natural Science Foundation of China, Excellent Young Scientists Fund (no.
51422404), General Program (no. 51774289), and NSFC, Shanxi Joint Fund for Coal-Based Low-Carbon Technology (no. U1710258). Special thanks are due to Dr. Batugina Irina Mikhailovna, member of the Russian Academy of Natural Sciences, who cooperated with Dr. Jing-li Zhao in doing research on coal bursts, prevention, and control at Huafeng Coal Mine.

\section{References}

[1] TB. Zhao, WY. Guo, YL. Tan, YC. Yin, LS. Cai, and JF. Pan, "Case Studies of Rock Bursts Under Complicated Geological Conditions During Multi-seam Mining at a Depth of 800 m," Rock Mechanics Rock Engineering, p. 26, 2018.

[2] C. Mark, "Coal bursts in the deep longwall mines of the United States," International Journal of Coal Science and Technology, vol. 3, no. 1, 2016.

[3] J. F. T. Agapito, R. R. Goodrich, and M. Moon, "Dealing with coal bursts at Deer Creek," Mining Engineering, vol. 49, no. 7, pp. 31-37, 1997.

[4] M. J. DeMarco, J. R. Koehler, and H. Maleki, "Gate road design considerations for mitigation of coal bumps in western U.S. longwall operations," in Proceedings of thE Mechanics and Mitigation of Violent Failure in Coal and Hard-Rock Mines. U.S. Department of the Interior, Bureau of Mines, SP 01-95, H. Maleki, PF. Wopat, RC. Repsher, RJ. Tuchman, and U. S. western, Eds., pp. 141-165, Spokane, WA, USA, 1995.

[5] V. V. Nazimko, "Pillarless longwall mining for multiple seams," Proc. 13th international conference, ground control in mining, Morgantown, WV, 1994, pp. 239-245, 1994.

[6] W. Li, J. Bai, S. S. Peng, X. Wang, and Y. Xu, "Numerical modeling for yield pillar design: a case study," Rock Mechanics and Rock Engineering, vol. 48, no. 1, pp. 305-318, 2015. 
[7] Y. L. Tan, F. H. Yu, J. G. Ning, and T. B. Zhao, "Design and construction of entry retaining wall along a gob side under hard roof stratum," International Journal of Rock Mechanics and Mining Sciences, vol. 77, pp. 115-121, 2015.

[8] H. Li, P. Syd, H. Li et al., "Trial of small gateroad pillar in top coal caving longwall mining of large mining height," International Journal of Mining Science and Technology, vol. 26, no. 1, pp. 139147, 2016.

[9] Z.-L. Li, L.-M. Dou, W. Cai, G.-F. Wang, Y.-L. Ding, and Y. Kong, "Roadway stagger layout for effective control of gob-side rock bursts in the longwall mining of a thick coal seam," Rock Mechanics and Rock Engineering, vol. 49, no. 2, pp. 621-629, 2016.

[10] Z. Zhang, J. Bai, Y. Chen, and S. Yan, "An innovative approach for gob-side entry retaining in highly gassy fullymechanized longwall top-coal caving," International Journal of Rock Mechanics and Mining Sciences, vol. 80, pp. 1-11, 2015.

[11] H. Yang, S. Cao, Y. Li, C. Sun, and P. Guo, "Soft roof failure mechanism and supporting method for gob-side entry retaining," Minerals, vol. 5, no. 4, pp. 707-722, 2015.

[12] S. Yan, J. Bai, X. Wang, and L. Huo, "An innovative approach for gateroad layout in highly gassy longwall top coal caving," International Journal of Rock Mechanics and Mining Sciences, vol. 59, pp. 33-41, 2013.

[13] M. Shabanimashcool and C. C. Li, "Numerical modelling of longwall mining and stability analysis of the gates in a coal mine," International Journal of Rock Mechanics and Mining Sciences, vol. 51, pp. 24-34, 2012.

[14] A.-Y. Cao, L.-M. Dou, C.-B. Wang, X.-X. Yao, J.-Y. Dong, and Y. Gu, "Microseismic Precursory Characteristics of Rock Burst Hazard in Mining Areas Near a Large Residual Coal Pillar: A Case Study from Xuzhuang Coal Mine, Xuzhou, China," Rock Mechanics and Rock Engineering, vol. 49, no. 11, pp. 4407-4422, 2016.

[15] J. Han, H. Zhang, B. Liang et al., "Influence of Large Syncline on In Situ Stress Field: A Case Study of the Kaiping Coalfield, China," Rock Mechanics and Rock Engineering, vol. 49, no. 11, pp. 4423-4440, 2016.

[16] P. Wang, J. Zhao, G. Feng, and Z. Wang, "Improving stress environment in development entries through an alternate longwall mining layout," Arabian Journal of Geosciences, vol. 11, no. 2, 2018.

[17] H. Wang, Y. Jiang, S. Xue, X. Pang, Z. Lin, and D. Deng, "Investigation of Intrinsic and External Factors Contributing to the Occurrence of Coal Bumps in the Mining Area of Western Beijing, China," Rock Mechanics and Rock Engineering, vol. 50, no. 4, pp. 1033-1047, 2016.

[18] J. Zhao, P. Wang, and Y. Su, "An innovative longwall mining technology in Tangshan coal mine, China," Minerals, vol. 7, no. 1, article no. 14, 2017.

[19] T. Zhao, W. Guo, Y. Tan, C. Lu, and C. Wang, "Case histories of rock bursts under complicated geological conditions," Bulletin of Engineering Geology and the Environment, pp. 1-17, 2017.

[20] Z. Li, L. Dou, W. Cai et al., "Investigation and analysis of the rock burst mechanism induced within fault-pillars," International Journal of Rock Mechanics and Mining Sciences, vol. 70, pp. 192200, 2014.

[21] S. Zhu, Y. Feng, and F. Jiang, "Determination of Abutment Pressure in Coal Mines with Extremely Thick Alluvium Stratum: A Typical Kind of Rockburst Mines in China," Rock Mechanics and Rock Engineering, vol. 49, no. 5, pp. 1943-1952, 2016.
[22] F. Q. Gao, D. Stead, and H. P. Kang, "Numerical simulation of squeezing failure in a coal mine roadway due to mininginduced stresses," Rock Mechanics and Rock Engineering, vol. 48, no. 4, pp. 1635-1645, 2015.

[23] Q.-S. Bai, S.-H. Tu, F.-T. Wang, X.-G. Zhang, H.-S. Tu, and Y. Yuan, "Observation and numerical analysis of the scope of fractured zones around gateroads under longwall influence," Rock Mechanics and Rock Engineering, vol. 47, no. 5, pp. 19391950, 2014.

[24] Y. Chen, S. Ma, and Y. Yu, "Stability Control of Underground Roadways Subjected to Stresses Caused by Extraction of a 10m-Thick Coal Seam: A Case Study," Rock Mechanics and Rock Engineering, vol. 50, no. 9, pp. 2511-2520, 2017.

[25] H. Wang, Y. Jiang, Y. Zhao, J. Zhu, and S. Liu, "Numerical investigation of the dynamic mechanical state of a coal pillar during longwall mining panel extraction," Rock Mechanics and Rock Engineering, vol. 46, no. 5, pp. 1211-1221, 2013.

[26] J. Wang, Z. Wang, and S. Yang, "A coupled macro- and meso-mechanical model for heterogeneous coal," International Journal of Rock Mechanics and Mining Sciences, vol. 94, pp. 6481, 2017.

[27] E. Hoek, C. T. Carranza-Torres, and B. Corkum, "Hoek-Brown failure criterion-2002 edition," in Proceedings of the Fifth North American Rock Mechanics Symposium (NARMS-TAC), R. Hammah, W. Bawden, J. Curran, and M. Telesnicki, Eds., pp. 267-273, University of Toronto Press, Toronto, Canada, 2002.

[28] RocData, 2016, https://www.rocscience.com/rocscience/products/ rocdata.

[29] M. Salamon, "Mechanism of caving in longwall coal mining MDG Salamon," in Proceedings of the Rock Mechanics Contributions and Challenges: Proceedings of the 31st US Symposium on Rock Mechanics, 1990.

[30] M. D. Pappas and C. Mark, Behavior of simulated longwall gob material. US Department of the Interior, Bureau of Mines, 1993.

[31] H. Yavuz, "An estimation method for cover pressure reestablishment distance and pressure distribution in the goaf of longwall coal mines," International Journal of Rock Mechanics and Mining Sciences, vol. 41, no. 2, pp. 193-205, 2004.

[32] M. Shabanimashcool and C. C. Li, "A numerical study of stress changes in barrier pillars and a border area in a longwall coal mine," International Journal of Coal Geology, vol. 106, pp. 39-47, 2013.

[33] Itasca, Fast Lagrangian Analysis of Continua in 3 dimension, Version 3.1, User's Guide, Minneapolis, Minn, USA, 2007.

[34] G.-C. Zhang, F.-L. He, H.-G. Jia, and Y.-H. Lai, "Analysis of Gateroad Stability in Relation to Yield Pillar Size: A Case Study," Rock Mechanics and Rock Engineering, vol. 50, no. 5, pp. 12631278, 2017.

[35] S. S. Peng, Longwall mining, Peng SS publisher, Morgantown, Va, USA, 2nd edition, 2006. 


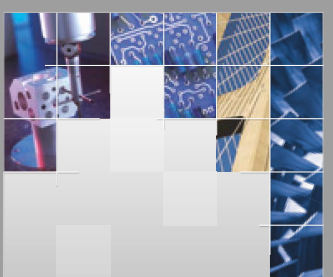

\section{Enfincering}
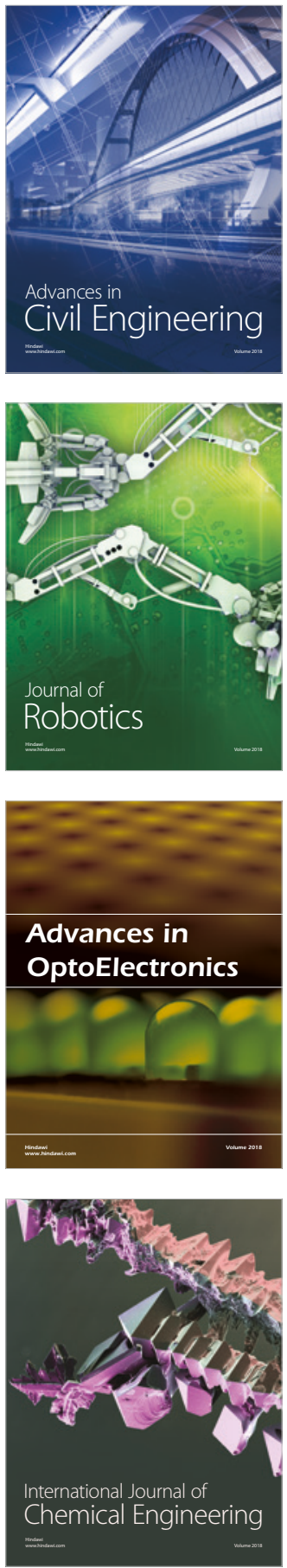

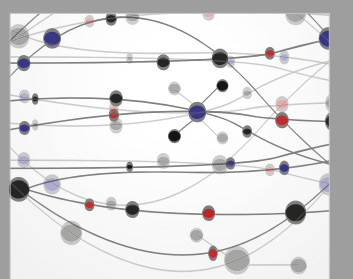

\section{Rotating \\ Machinery}

The Scientific World Journal

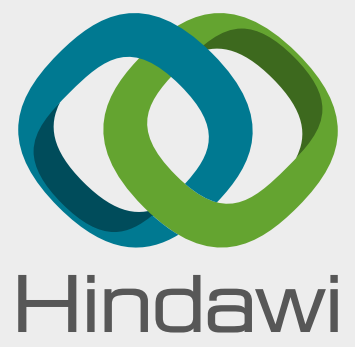

Submit your manuscripts at

www.hindawi.com
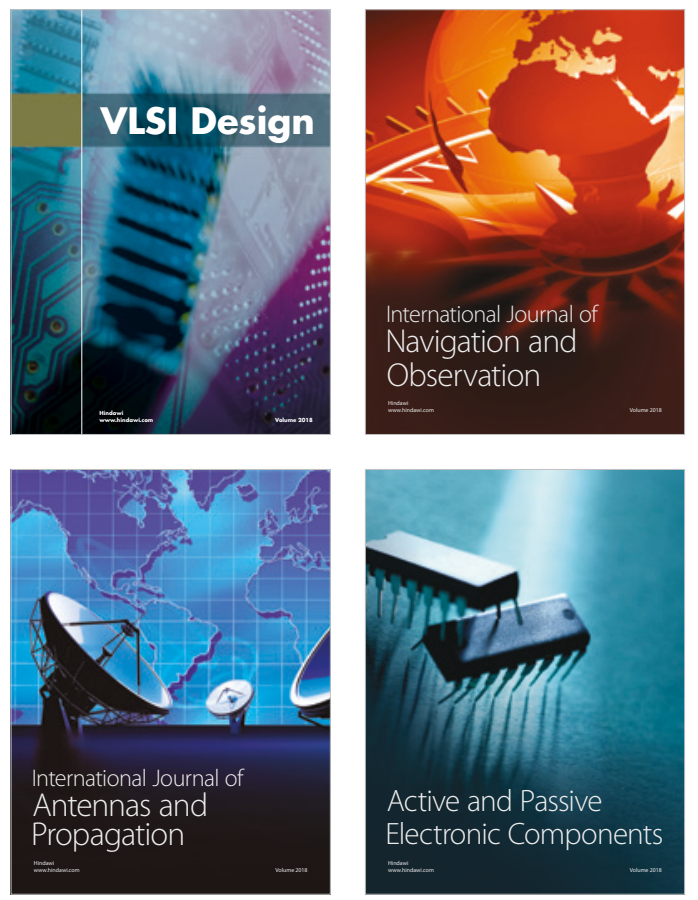
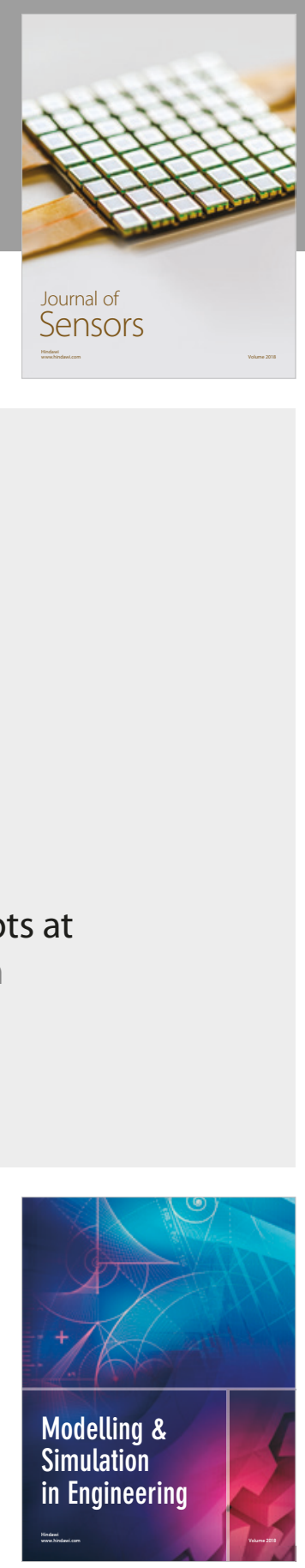

\section{Advances \\ Multimedia}
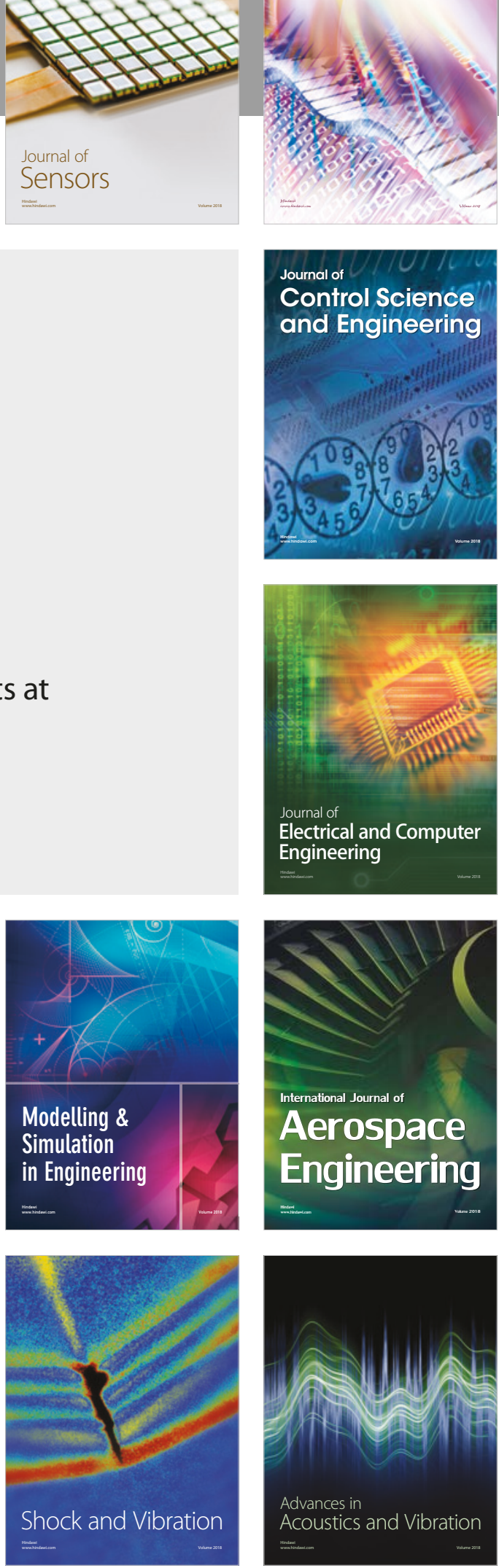